\title{
Tuning the Cation Ordering with the Deposition Pressure in Sputtered LiMn1.5Ni0.5O4 Thin Film Deposited on Functional Current Collectors for Li-Ion Microbattery Applications
}

Manon Létiche, Maxime Hallot, Marielle Huve, Thierry Brousse, Pascal Roussel, C. Lethien

\section{To cite this version:}

Manon Létiche, Maxime Hallot, Marielle Huve, Thierry Brousse, Pascal Roussel, et al.. Tuning the Cation Ordering with the Deposition Pressure in Sputtered LiMn1.5Ni0.5O4 Thin Film Deposited on Functional Current Collectors for Li-Ion Microbattery Applications. Chemistry of Materials, American Chemical Society, 2017, 29, pp.6044 - 6057. 10.1021/acs.chemmater.7b01921 . hal-03192879

\section{HAL Id: hal-03192879 \\ https://hal.archives-ouvertes.fr/hal-03192879}

Submitted on 8 Apr 2021

HAL is a multi-disciplinary open access archive for the deposit and dissemination of scientific research documents, whether they are published or not. The documents may come from teaching and research institutions in France or abroad, or from public or private research centers.
L'archive ouverte pluridisciplinaire HAL, est destinée au dépôt et à la diffusion de documents scientifiques de niveau recherche, publiés ou non, émanant des établissements d'enseignement et de recherche français ou étrangers, des laboratoires publics ou privés. 


\title{
Tuning the Cation Ordering with the Deposition Pressure in Sputtered LiMn ${ }_{1.5} \mathrm{Ni}_{0.5} \mathrm{O}_{4}$ Thin Film Deposited on Functional Current Collectors for Li-Ion Microbattery Applications
}

\author{
Manon Létiche, ${ }^{\S, \ddagger}, \perp$ Maxime Hallot, ${ }^{\S, \perp}$ Marielle Huvé, ${ }^{\ddagger}$ Thierry Brousse, ${ }^{\perp, \dagger}$ Pascal Roussel, ${ }^{*}, \ddagger$ \\ and Christophe Lethien $*, \S, \perp_{(0)}$ \\ ${ }^{\S}$ Institut d'Electronique, de Microélectronique et de Nanotechnologies, Université de Lille, CNRS, Centrale Lille, ISEN, Université de \\ Valenciennes, UMR 8520 - IEMN, F-59000 Lille, France \\ ${ }^{\ddagger}$ Unité de Catalyse et de Chimie du Solide (UCCS), Université de Lille, CNRS, Centrale Lille, ENSCL, Université d'Artois, UMR \\ 8181 - UCCS, F-59000 Lille, France \\ ${ }^{\perp}$ Réseau sur le Stockage Electrochimique de l'Energie, CNRS FR 3459, 33 rue Saint Leu, 80039 Amiens Cedex, France \\ ${ }^{\dagger}$ Institut des Matériaux Jean Rouxel (IMN), CNRS UMR 6502, Université de Nantes, 2 rue de la Houssinière BP32229, 44322 \\ Nantes cedex 3, France
}

ABSTRACT: The development of high voltage spinel $\mathrm{LiMn}_{1.5} \mathrm{Ni}_{0.5} \mathrm{O}_{4}$ (LMNO) sputtered thin films on functional current collector was reported within the framework of this study. We have first solved the technological issue due to the PtSi phase which originates from the interdiffusion between silicon wafer and chromium/platinum current collector to form $\mathrm{PtSi}$ phase under annealing treatment. By substituting the $\mathrm{Cr}$ layer with a very dense and pinhole free $\mathrm{Al}_{2} \mathrm{O}_{3}$ thin film deposited by ALD acting as a barrier diffusion between the silicon substrate and the LMNO layer, the synthesis process (sputtered thin films annealed under air at $700{ }^{\circ} \mathrm{C}$ ) has been validated. In the second part of this study, the behavior of the sputtered LMNO thin films as a

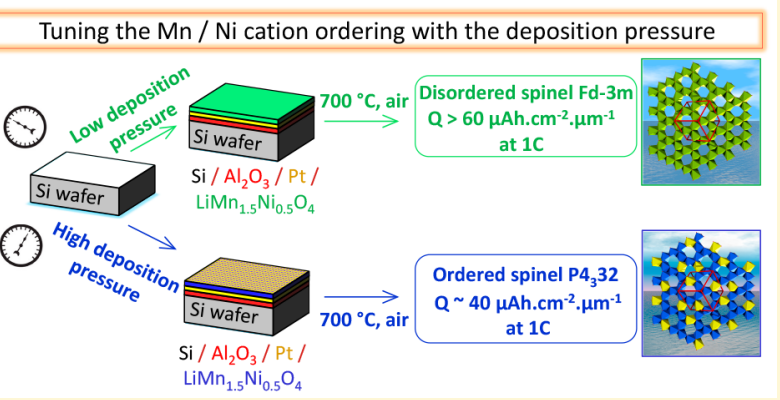
function of the deposition pressure and the film thickness has been investigated. The deposition pressure has been found to play a key role on the $\mathrm{Mn}-\mathrm{Ni}$ cations ordering in spinel-like structures $\left(P 4_{3} 32\right.$ ordered vs $F \bar{d} \overline{3} m$ disordered spinel) and consequently on the electrochemical performance. We have thus shown that LMNO thin films deposited at $10^{-2}$ mbar and annealed at $700{ }^{\circ} \mathrm{C}$ deliver a normalized capacity of $65 \mu \mathrm{Ah} \cdot \mathrm{cm}^{-2} \cdot \mu \mathrm{m}^{-1}$ with good capacity retention upon cycling thanks to its disordered spinel structure. Moreover, the Coulombic efficiency has been shown to be highly dependent on the film thickness for high voltage LMNO thin film electrodes. To the best of the authors' knowledge, this work is one of the most complete study combining structural and electrochemical characterizations of the LMNO thin film obtained by sputtering deposition on $\mathrm{Si} / \mathrm{Al}_{2} \mathrm{O}_{3} / \mathrm{Pt}$ functional current collectors.

\section{INTRODUCTION}

Nowadays, connected electronic devices such as smartphones or tablets are widespread within the society. The trends for the next ten years is to move toward the Internet of Thing (IoT) concept where physical devices embedding electronics and sensors are connected together to collect and exchange data. Unfortunately, the main bottleneck slowing the development of smart and miniaturized sensors lies in the fabrication of high performance power sources at the millimeter scale. All solid state Li-ion microbatteries seem to be interesting candidates, but the energy densities of such commercially available devices are limited $\left(0.5 \mathrm{mWh} \cdot \mathrm{cm}^{-2}\right)$ in spite of a high technological readiness level (industrial level). Getting autonomous miniaturized and connected sensors will be unachievable if the energy density is not significantly increased.

To improve the energy density of the Li-ion microbattery, an attractive solution consists of increasing the nominal cell voltage using high potential positive electrode material deposited using thin film technology. The use of Ni substituted $\mathrm{LiMn}_{2} \mathrm{O}_{4}$ spinel material and their derivatives is really promising. ${ }^{1}$ Indeed, the spinel $\mathrm{LiMn}_{1.5} \mathrm{Ni}_{0.5} \mathrm{O}_{4}$ (LMNO) exhibits a mean operating potential of $4.75 \mathrm{~V}$ vs $\mathrm{Li} / \mathrm{Li}^{+}$, a theoretical specific capacity of $147 \mathrm{mAh} \cdot \mathrm{g}^{-1}$, and a good cycling stability despite the decomposition of standard liquid electrolytes at such a high potential. ${ }^{2}$ As the performance of power sources per mass unity is not really meaningful for miniaturized devices, it makes sense to report on the storage capacity using either the footprint area or the volume (footprint $\times$ thickness) of the electrode. Therefore, assuming a bulk density of $4.47 \mathrm{~g}$. $\mathrm{cm}^{-3}$, the corresponding volumetric capacity is found to be

Received: May 10, 2017

Revised: June 21, 2017

Published: June 21, 2017 


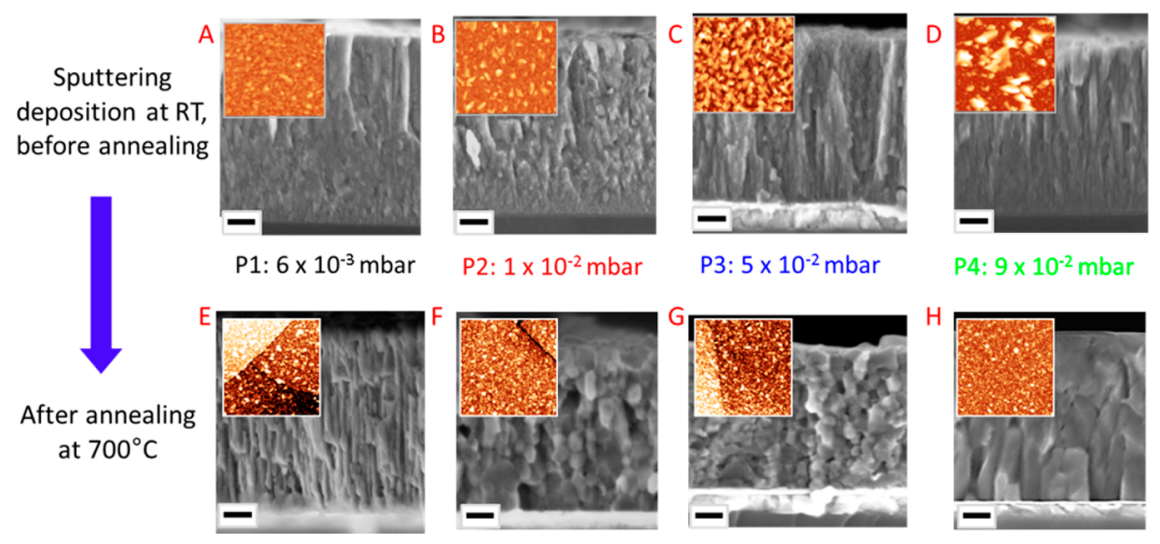

Figure 1. SEM cross sections (bare scale $=100 \mathrm{~nm}$ ) and top surface (AFM scanning area $=5 \mu \mathrm{m} \times 5 \mu \mathrm{m}$ ) analyses of as-deposited LMNO thin films as a function of the deposition pressure, from $6 \times 10^{-3}$ up to $9 \times 10^{-2} \mathrm{mbar}(\mathrm{A}-\mathrm{D})$. SEM fracture and top surface $($ AFM scanning area $=5 \mu \mathrm{m} \times 5$ $\mu \mathrm{m})$ analyses of the four studied LMNO layers annealed at $700{ }^{\circ} \mathrm{C}(\mathrm{E}-\mathrm{H})$.

close to $65.7 \mu \mathrm{Ah} \cdot \mathrm{cm}^{-2} \cdot \mu \mathrm{m}^{-1}$. This density is strongly dependent upon the material porosity. As an example, shadowing effect occurring during sputtering deposition, when adsorbed atoms mobility is low, is known to be responsible for porous thin film morphology. ${ }^{3-5}$

LMNO thin films have already been deposited by several techniques such as electrostatic spray deposition, ${ }^{6}$ sol-gel, ${ }^{7,8}$ pulsed laser deposition ${ }^{9-11}$ (PLD), and RF magnetron sputtering deposition. ${ }^{12-15}$ Among these techniques, magnetron sputtering (MS) is widely used for the elaboration of thin film electrodes such as $\mathrm{LiMn}_{2} \mathrm{O}_{4}, \mathrm{LiCoO}_{2}$, or $\mathrm{LiFePO}_{4}$ (positive electrodes $\left.^{16-19}\right)$, current collectors (W, $\mathrm{Al}, \mathrm{Cu}$ ), and lithium diffusion barriers ${ }^{4,20}(\mathrm{TiN})$, solid electrolytes ${ }^{21-23}$ (LIPON), and $\mathrm{Au}, \mathrm{Ag}, \mathrm{Si}$, or $\mathrm{CuO}$ for the negative electrodes. ${ }^{24-26} \mathrm{An}$ allsolid-state thin film microbattery can be described as a stack of successive layers including the adhesive/insulating layer, the current collectors, the active materials (negative and positive electrodes separated by a solid electrolyte), and protective layers (hence at least seven layers). While "classical" studies focus only on the deposition of active material on commercial current collectors $(\mathrm{Pt}, \mathrm{Ti}, \mathrm{Cu}$, stainless steel, or $\mathrm{Al}$ foils ${ }^{10,11,27-29}$ ), we propose in this paper to investigate the stacking of the first layers (from the substrate to the positive electrode) to fully understand, and further to control, the influence of the underlying layer (interdiffusion process, preferred orientation) on the active material of the microbattery. The ultimate goal is actually to develop a synthesis process easy scalable using microelectronic manufacturing.

Subsequently, we mainly focused on the elaboration of LMNO thin film by radiofrequency (RF) MS deposition. Among all the synthesis parameters (RF power, deposition time, pressure, temperature, etc.), a preliminary study has shown that the deposition pressure within the chamber and the afterward annealing temperature were key parameters to meet the electrochemical performance requirements. The investigation of the deposition pressure on the microstructure, the surface morphology, the $\mathrm{Mn}-\mathrm{Ni}$ cation ordering in the structure of LMNO thin films deposited by MS, and the electrochemical performance are reported in the present paper. The influence of the film thickness is also reported as a key parameter that can improve both the surface capacity and the Coulombic efficiency of Li-ion microbatteries.

\section{EXPERIMENTAL SECTION}

Film Preparation. Prior to LMNO thin films deposition, layers of $\mathrm{Cr}$ and Pt were first evaporated on (100) silicon wafer as adhesive and current collector layers, respectively. Consequently to the formation of an unexpected phase $(\mathrm{PtSi})$ responsible for poor electrochemical performances of the material when the LMNO thin film is annealed at high temperature, the $\mathrm{Cr}$ layer was replaced by an $\mathrm{Al}_{2} \mathrm{O}_{3}$ layer deposited by atomic layer deposition (ALD) in a Picosun R200 reactor.

LMNO thin films were deposited by radiofrequency magnetron sputtering. The CT 200 cluster sputtering equipment has been used to achieve the thin film deposition after pumping to a base vacuum of $10^{-7}$ mbar. Homogeneous deposits were obtained by keeping the distance between the target and the substrate at $60 \mathrm{~mm}$. A pure $\mathrm{LiMn}_{1.5} \mathrm{Ni}_{0.5} \mathrm{O}_{4}$ target $(99.999 \%, 10 \mathrm{~cm}$ diameter, $6 \mathrm{~mm}$ thick) was sputtered under argon atmosphere in the CT 200 sputtering equipment (Alliance Concept). Four operating pressures have been studied: $6 \times 10^{-3}, 10^{-2}, 5 \times 10^{-2}$, and $9 \times 10^{-2} \mathrm{mbar}$, respectively. The argon flow rate is kept constant close to $50 \mathrm{sccm}$ for all the deposition pressures as well as the RF power used to bias the target $\left(2.7 \mathrm{~W} \cdot \mathrm{cm}^{-2}\right)$. In a preliminary study, three annealing temperatures were investigated $\left(650,700\right.$, and $\left.750{ }^{\circ} \mathrm{C}\right)$. The optimized electrochemical performances of the LMNO thin films were achieved using a $700{ }^{\circ} \mathrm{C}$ annealing temperature. Subsequently, LMNO thin films were annealed under air atmosphere at $700{ }^{\circ} \mathrm{C}$ for $2 \mathrm{~h}$ (dwell) with a heating/cooling ramp of 5 ${ }^{\circ} \mathrm{C} / \mathrm{min}$. Finally, the deposition time has been tuned to deposit LMNO thin films with different thicknesses.

Sample Morphological and Structural Characterization. The thickness and microstructure of the films were determined using the scanning electron microscope (SEM Zeiss supra 55-VP). The surface morphology was analyzed by AFM Dimension 3100 ICON (Bruker) measurements operated under ambient conditions. Images were acquired in the tapping/peak force tapping mode with a Mikromach tap 300-Al cantilever. The scanning rate was $0.5 / 1 \mathrm{~Hz}$, and $5 \mu \mathrm{m} \times 5$ $\mu \mathrm{m}$ images were obtained. The mechanical stress has been investigated by measuring the curvature radius of a $3 \mathrm{in}$. $\mathrm{Si}(100)$ wafer before and after deposition of LMNO thin film. A Rigaku SMARTLAB multipurpose six-axis diffractometer $(9 \mathrm{~kW}$ rotating anode) using $\mathrm{Cu}$ $\mathrm{K} \alpha$ radiation $(\lambda=1.5418 \AA)$ and a Horiba Jobin Yvon LabRam HR UV Raman spectrometer with a $471 \mathrm{~nm}$ UV laser source were used to identify the structure type and the polymorph (ordered/disordered) of the films, respectively. XRD in plane pole figures was recorded as a series of phi values (from 0 to $360^{\circ}$ ) at different chi values (from 0 to $\left.90^{\circ}\right)$ for a fixed 2 theta angle depending on the recorded planes $(2$ theta $=36.44^{\circ}$ for the 311 peak and $44.31^{\circ}$ for the 400 ones). Transmission electron microscopy (TEM) studies were performed on FEI Technai G220 and Philips CM30 microscopes equipped with an EDS spectrometer. Cross-sectional samples were prepared by focused ion beam (FIB) technique. $\mathrm{Li}, \mathrm{Ni}$, and $\mathrm{Mn}$ contents were measured 

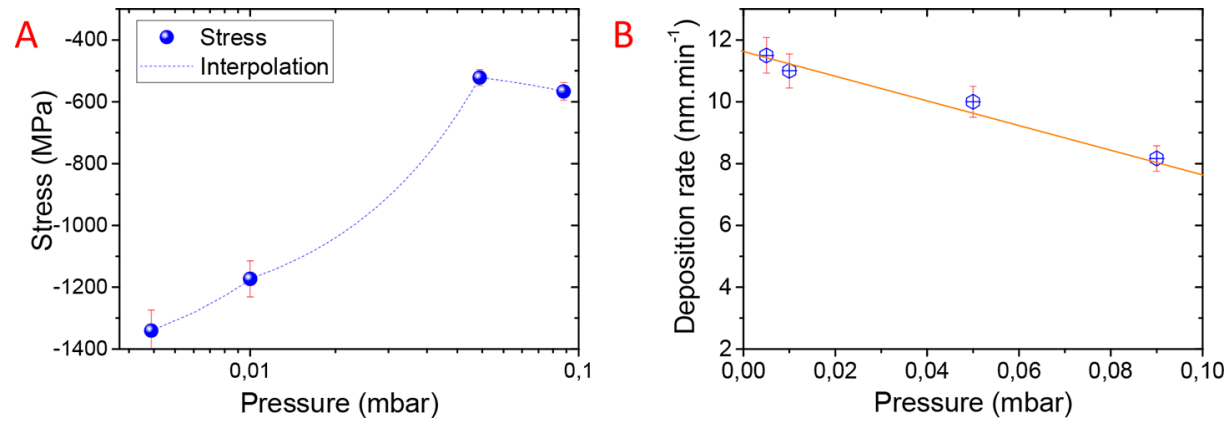

Figure 2. Evolution of the intrinsic stress (A) and the deposition rate (B) as a function of the operating pressure.

using an inductively coupled plasma-Auger emission spectrometer (ICP-AES) (Varian 700ES) by dissolving beforehand thin films deposited on the $\mathrm{Si}$ substrate in $2 \mathrm{~mL}$ of $\mathrm{HCl}$ and $1 \mathrm{~mL}$ of $\mathrm{HNO}_{3}$. An aliquot of each solution was analyzed by the atomic absorption spectrometry. The wavelengths of the emission lines are $460.289 \mathrm{~nm}$ for $\mathrm{Li}, 259.372 \mathrm{~nm}$ for $\mathrm{Mn}$, and $221.348 \mathrm{~nm}$ for $\mathrm{Ni}$, respectively.

Electrochemical Characterization. Electrochemical measurements were conducted in homemade flat cells operated in an $\mathrm{Ar}$ filled glovebox. The cells were assembled with LMNO thin film as positive electrode and pure $\mathrm{Li}$ as counter and reference electrode. A mixture of $1 \mathrm{M} \mathrm{LiClO}_{4}$ dissolved in ethyl carbonate (EC)/dimethyl carbonate (DMC) (1:1) was used as the liquid electrolyte. The electrochemical properties of LMNO thin films deposited at different pressures and annealed at $700{ }^{\circ} \mathrm{C}$ were characterized. Galvanostatic cycling, cyclic voltamperometry, and electrochemical impedance spectroscopy (EIS) were performed with a Biologic VMP3 potentiostat/galvanostat. Electrochemical impedance spectroscopy spectra were recorded between $100 \mathrm{kHz}$ and $5 \mathrm{mHz}$ with an AC voltage of $10 \mathrm{mV}$. This frequency range is restricted between $500 \mathrm{~Hz}$ and $5 \mathrm{mHz}$ when ionic conductivity and diffusion coefficient are extracted from the slope of the Warburg impedance as a function of the square root of the angular frequency (linear region).

\section{RESULTS AND DISCUSSION}

Microstructural and Morphological Characterization of As Deposited Thin Films. Figure 1A-D depicts the SEM cross section and the AFM top surface observations of as deposited LMNO thin films obtained at different pressure conditions $(0.4 \mu \mathrm{m}$ thick $)$. A microstructural evolution is clearly evidenced.

The melting temperature of the $\mathrm{LMNO}$ is close to the one of the $\mathrm{LiMn}_{2} \mathrm{O}_{4}$ spinel compound ${ }^{30}(1700 \mathrm{~K})$. Consequently, the $T / T_{\mathrm{m}}$ ratio is lower than 0.2 for LMNO deposited at room temperature, and as expected, the film morphology is found to be in zone $\mathrm{T}$ from the Thornton ${ }^{31}$ structure zone model (SZM). As a matter of fact, at low pressure, the LMNO films exhibit highly dense and homogeneous morphologies, whereas at higher pressures, the microstructure is found to be more columnar and porous (Zone 1 of the Thornton SZM). The observed morphology at low pressure results from the film densification which is a direct consequence of the atomic peening effect where high energy atoms strike the film surface under growth and induce atomic resputtering in the column boundaries. ${ }^{32}$ The surface analysis as a function of the deposition pressure is depicted in the insets of Figure $1 \mathrm{~A}-$ D. At low pressures $\left(6 \times 10^{-3}\right.$ and $\left.10^{-2} \mathrm{mbar}\right)$, few small grains randomly distributed can be similarly noticed on the surface. Hence the surface roughness is very low $(6-8 \mathrm{~nm})$. At higher pressures $\left(5 \times 10^{-2}\right.$ and $\left.9 \times 10^{-2} \mathrm{mbar}\right)$, the size and the number of the random grains is increased which significantly enhances the surface roughness $(20 \mathrm{~nm})$. The films were then annealed under air atmosphere for $2 \mathrm{~h}$ at $700{ }^{\circ} \mathrm{C}$. The SEM cross section analysis of the corresponding films is depicted in Figure $1 \mathrm{E}-\mathrm{H}$. At low pressure, the microstructure is kept dense but a columnar-like structure is highlighted. When the pressure is increased, the morphology of annealed thin films moves from a porous columnar-like structure to a porous granular-like structure.

One attractive solution to increase the energy density of the planar thin film microbattery is to deposit a thicker layer of active material. However, the LMNO microstructure has to remain stable, i.e., without any cracks or failures, a problem often encountered when higher thickness is achieved. Indeed, it is well-known that the mechanical stress of dense thin films should be carefully tuned when the level of pressure is significantly low. Regarding the film morphology observed in Figure 1, a dense LMNO layer is obtained at low deposition pressure and the film densification is a consequence of the ion peening effect. Subsequently, the growth stress induced by the LMNO deposition on the silicon wafer has been investigated. For that purpose, the curvature radius before and after LMNO thin film deposition has been measured. The growth stress $\sigma_{\text {growth }}$ is calculated according to Stoney formula 1 :

$$
\sigma_{\text {growth }}=\frac{1}{6} \frac{E_{\mathrm{Si}}}{1-\nu_{\mathrm{Si}}} \frac{t_{\mathrm{Si}}^{2}}{t_{\mathrm{LMNO}}}\left(\frac{1}{R_{\mathrm{LMNO}}}-\frac{1}{R_{\mathrm{Si}}}\right)
$$

where $E_{\mathrm{Si}}$ is the Young modulus of the substrate (130 GPa for the silicon wafer), $\nu_{\mathrm{Si}}$ is the Poisson coefficient of the silicon substrate $(0.27)$, and $t_{\mathrm{Si}}$ and $t_{\mathrm{LMNO}}$ are respectively the thickness of the substrate $(380 \pm 15 \mu \mathrm{m})$ and the deposited film $(0.4 \mu \mathrm{m}$ in our deposition conditions). The bending radius of the LMNO ( $\left.R_{\text {LMNO }}\right)$ is measured just after the sputtering deposition and compared with the initial one $\left(R_{\mathrm{Si}_{\mathrm{i}}}\right)$, i.e., before the deposition.

As it is shown in Figure 2A, the thin film deposited at $6 \times$ $10^{-3}$ mbar exhibits a highly compressive intrinsic stress around $-1350 \mathrm{MPa}$. Then, the growth stress is relaxed starting from a critical pressure located between $10^{-2}$ and $5 \times 10^{-2}$ mbar, which is a true asset to reach high thickness without any cracks or failures in the films. The deposition rate is also slightly affected, decreasing from 11 down to $8 \mathrm{~nm} \cdot \mathrm{min}^{-1}$ when the pressure is increased (Figure 2B). For similar deposition time, the LMNO films are thus thinner at high pressure. From this analysis, it is clear that deposition pressure is a key parameter allowing the microstructure and the morphology of the LMNO films to be tailored while keeping the thin film strongly adhesive on the substrate. The stress of the sputtered LMNO thin films has been reduced after the annealing process as already observed in refs 33 and 34 on other thin film materials $\left(\mathrm{B}_{4} \mathrm{C}, \mathrm{W}\right)$, probably owing to the formation of voids within the 

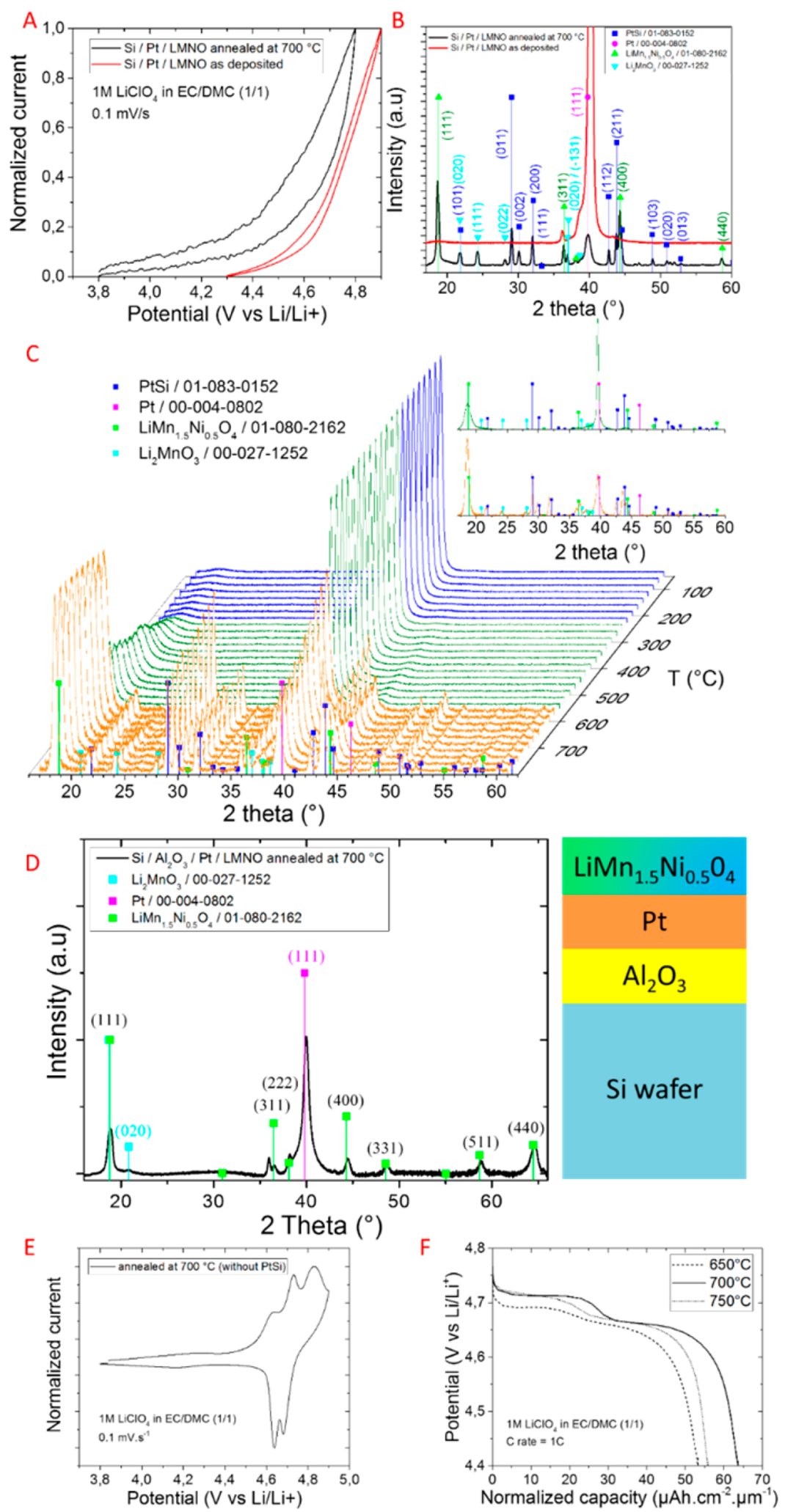

Figure 3. Illustration of the PtSi phase formation. A. Cyclic voltammetry of the as-deposited and $\left(700{ }^{\circ} \mathrm{C}\right)$ annealed $\mathrm{LMNO} / \mathrm{Pt} / \mathrm{Cr} / \mathrm{Si}$ samples between 3.8 (or 4.2 ) and $4.9 \mathrm{~V} \mathrm{vs} \mathrm{Li} / \mathrm{Li}^{+}$at $0.1 \mathrm{mV} \cdot \mathrm{s}^{-1}$. B. Diffractogramms of the as-deposited and annealed $\mathrm{LMNO} / \mathrm{Pt} / \mathrm{Cr} / \mathrm{Si} \mathrm{sample} \mathrm{at} 700{ }^{\circ} \mathrm{C}$. C. $\mathrm{HT}$-XRD analysis of the as-deposited $\mathrm{LMNO} / \mathrm{Pt} / \mathrm{Cr} / \mathrm{Si}$ sample from 50 to $800{ }^{\circ} \mathrm{C}$. D. High temperature $\mathrm{XRD}$ patterns of the $\mathrm{LMNO} / \mathrm{Pt} / \mathrm{Al}_{2} \mathrm{O}_{3} / \mathrm{Si}$ sample, i.e., where the $\mathrm{Cr}$ adhesive layer has been replaced by an $\mathrm{Al}_{2} \mathrm{O}_{3}$ insulating layer. E. Cyclic voltammetry of the $\mathrm{LMNO} / \mathrm{Pt} / \mathrm{Al}{ }_{2} \mathrm{O}_{3} / \mathrm{Si}$ sample annealed at $700{ }^{\circ} \mathrm{C}$ demonstrating the redox activity of nickel cations at $4.7 \mathrm{~V} \mathrm{vs} \mathrm{Li} / \mathrm{Li}^{+}$. F. constant current galvanostatic charge-discharge between 4.4 and $4.8 \mathrm{~V}$ vs $\mathrm{Li} / \mathrm{Li}^{+}$at $1 \mathrm{C}$ rate as a function of the normalized capacity reported regarding the annealing temperature $\left(650,700\right.$, and $\left.750{ }^{\circ} \mathrm{C}\right)$. From this study, an annealing temperature of $700{ }^{\circ} \mathrm{C}$ seems to maximize the normalized capacity. 
thin films as depicted on the SEM cross sections shown in Figure 1 or due to the crystallization process. Subsequently, an in-depth study dealing with the influence of the pressure on LMNO structural and electrochemical properties is proposed in the following paragraphs. The LMNO morphology exhibits a porous shape after an annealing at $700{ }^{\circ} \mathrm{C}$ as depicted in the SEM cross sections reported in Figure 1. Such morphology is quite interesting when the LMNO thin film is cycled in liquid electrolyte because the liquid fills the porous morphology. Consequently, the surface capacity is increased as compared to the electrochemical performance reached with dense thin films. This remark is questionable for future solid state microbatteries based on sputtered thin films. The most investigated solid electrolyte is LiPON where $1 \mu$ m-thick layer ${ }^{22,23}$ has to be deposited to act as good electronic insulator and a good $\mathrm{Li}^{+}$ ionic conductor between the two electrodes. Sputtering technique is known to be unadaptable to achieve the deposition of a uniform/homogeneous coating inside micro/mesoporous structure. As a matter of fact, the thickness of the sputtered LMNO will not be totally active if LiPON deposition is performed on such a porous thin film because the LiPON deposition will not enter through the entire film thickness. Nevertheless, the actual trend is to reduce the electrolyte thickness in order to decrease the resistivity of the full cell and to produce a pinhole free layer. Atomic layer deposition (ALD) of lithiated solid electrolyte $e^{35-37}$ is now widely developed. As ALD is known to be a powerful technique to coat micro-/ mesoporous structure with a pinhole free thin layer $(<100 \mathrm{~nm})$, such LMNO morphology is quite interesting when combined with ALD deposited solid electrolyte. We have recently demonstrated the growth of $10 \mathrm{~nm}$ - and up to $60 \mathrm{~nm}$-thick $\mathrm{Li}_{3} \mathrm{PO}_{4}$ solid electrolyte on a $3 \mathrm{D}$ complex surface to act as a good ionic conductor and electronic insulator for a thin film microbattery. $^{35}$

Classical techniques such as BET measurement could not be used to evaluate the porosity of thin films due to the small quantity of active material as compared to bulk material. Hence, we evaluate the bulk density of thin film $\left(\mathrm{g} \cdot \mathrm{cm}^{-3}\right)$ by measuring the mass of the substrate before and after the deposition using a XP6U Mettler Toledo microbalance $( \pm 0.1 \mu \mathrm{g}$ accuracy). Taking into account the surface of the sample as well as the thickness of the layer, the volume of active material is deduced. The measured bulk density is estimated to be $80 \%$ of the theoretical value.

Influence of the Substrate: Formation of the PtSi Phase at High Temperature Annealing. First, LMNO thin films $(0.4 \mu$ m-thick $)$ were deposited at $10^{-2}$ mbar on $\mathrm{Cr}(20$ $\mathrm{nm}) / \mathrm{Pt}(50 \mathrm{~nm})$ coated silicon wafer, i.e., a typical electrical current collector used in microelectronic applications. The CVs of the as-deposited and $700{ }^{\circ} \mathrm{C}$ annealed LMNO samples are displayed in Figure 3A. If the electrochemical signature is the one expected for the nonannealed sample (absence of redox peaks within the studied electrochemical windows between 3.8 $\mathrm{V}$ (or $4.2 \mathrm{~V}$ ) and $4.9 \mathrm{~V}$ vs $\mathrm{Li} / \mathrm{Li}^{+}$), the annealed sample has to be electrochemically active.

To answer this question, this issue has been investigated by $\mathrm{X}$-ray diffraction analysis (XRD). From the corresponding patterns (Figure 3B) it is clear that the only visible diffraction peak is due to the (111) plane of the platinum layer as expected on the as-deposited sample, leading to the conclusion that this sample is amorphous (red curve). After a $2 \mathrm{~h}$ annealing at 700 ${ }^{\circ} \mathrm{C}$ under air atmosphere, reflection peaks related to the LMNO spinel structure (JCPDS PDF 01-080-2162) can be observed (as awaited), but two additional phases are also evidenced. Indeed, another lithiated phase $\mathrm{Li}_{2} \mathrm{MnO}_{3}$ (JCPDS PDF 00-0271252) can be identified as well as an unexpected PtSi (JCPDS PDF 01-083-0152) phase triggering a significant decrease of the platinum (111) Bragg peak at $2 \theta=40^{\circ}$. However, from an electrochemical point of view, none of these phases should be responsible for the bad electrochemical behavior of the film annealed at $700{ }^{\circ} \mathrm{C}$. Indeed, $\mathrm{Li}_{2} \mathrm{MnO}_{3}$ exhibits an irreversible $\mathrm{Li}_{2} \mathrm{O}$ loss above $4.6 \mathrm{~V}$, and $\mathrm{PtSi}$ has no electrochemical activity within this potential window. However, the $\mathrm{PtSi}$ phase is likely damaging the current collector. In situ HT-XRD (high temperature X-ray diffraction) analysis has thus been undertaken on the as-deposited sample to investigate this $\mathrm{PtSi}$ issue vs crystallization of the LMNO thin films. XRD patterns have been recorded every $25{ }^{\circ} \mathrm{C}$ from 50 to $800{ }^{\circ} \mathrm{C}$ during annealing treatment in order to determine the annealing temperature required to obtain the $\mathrm{LMNO}$ phase without PtSi formation. Three steps are clearly highlighted (Figure 3C). From 50 to $225{ }^{\circ} \mathrm{C}$ the thin film is amorphous, and only the platinum reflection can be seen. From RT to $575{ }^{\circ} \mathrm{C}$ the (111) reflection peak of $\mathrm{LMNO}$ is raising. At $575{ }^{\circ} \mathrm{C}$, the $\mathrm{LMNO}$ spinel structure is identified as well as the $\mathrm{Li}_{2} \mathrm{MnO}_{3}$ phase and $\mathrm{PtSi}$ additional phases while the intensity of the (111) Pt peak drastically declines. This HT-XRD experiment clearly provides evidence that it is impossible to obtain only the spinel-like structure avoiding the $\mathrm{PtSi}$ phase formation. According to these results, we replaced the $\mathrm{Cr}$ adhesive layer by an $\mathrm{Al}_{2} \mathrm{O}_{3}(70 \mathrm{~nm})$ thin film deposited by ALD, which is expected to be very dense and able to prevent the $\mathrm{Pt}-\mathrm{Si}$ interdiffusion responsible for the formation of the $\mathrm{PtSi}$ alloy. The XRD analysis corresponding to this new $\mathrm{Si} / \mathrm{Al}_{2} \mathrm{O}_{3} / \mathrm{Pt} / \mathrm{LMNO}$ sample annealed at $700{ }^{\circ} \mathrm{C}$ is depicted in Figure 3D. Subsequently, only the reflection peaks of the platinum layer and those of the LMNO cathode (with a small contribution of the $\mathrm{Li}_{2} \mathrm{MnO}_{3}$ phase) are visible. Thus, the $\mathrm{PtSi}$ issue has been successfully solved. To the author's knowledge, this issue has never been evidenced in this context before and demonstrates that a careful control of the stacked layers has to be carried out in order to design sustainable microbatteries. Figure 3E displays the typical electrochemical signature of LMNO during the first cycle showing a redox activity around $4.7 \mathrm{~V}$ vs $\mathrm{Li} / \mathrm{Li}^{+}$. The double peaks in the $\mathrm{CV}$ appearing during the oxidation $\left(4.7\right.$ and $4.8 \mathrm{~V}$ vs $\left.\mathrm{Li} / \mathrm{Li}^{+}\right)$and reduction processes $\left(4.65\right.$ and $4.70 \mathrm{~V}$ vs $\left.\mathrm{Li} / \mathrm{Li}^{+}\right)$are related to the reversible redox activity of the nickel transition metal from $\mathrm{Ni}^{2+}$ to $\mathrm{Ni}^{4+}$. An additional oxidation peak is depicted at $4.6 \mathrm{~V}$ vs $\mathrm{Li} / \mathrm{Li}^{+}$owing to the presence of $\mathrm{Li}_{2} \mathrm{MnO}_{3}$ phase and subsequent oxygen evolution. ${ }^{38}$ One pair of minor peaks is found around $4 \mathrm{~V}$ vs $\mathrm{Li} / \mathrm{Li}^{+}$and could be attributed to the redox reaction of $\mathrm{Mn}^{3+/ 4+}$ which corroborates the existence of a small amount of $\mathrm{Mn}^{3+}$ ions inside the film. Those peaks have already been observed on bulk and thin film $\mathrm{LiMn}_{1.5} \mathrm{Ni}_{0.5} \mathrm{O}_{4}$ electrodes owing to nickel or oxygen deficiency. ${ }^{10,39}$ The electrochemical signature of the sputtered LMNO thin films also suggests that the $\mathrm{PtSi}$ phase was responsible for the inhibition of the LMNO electrochemical signal as previously observed. In Figure 3F, the evolution of the potential as a function of the normalized capacity between 4.4 and $4.8 \mathrm{~V}$ vs $\mathrm{Li} / \mathrm{Li}^{+}$is reported at a $1 \mathrm{C}$ cycling rate regarding the annealing temperature (the second cycle is shown). These constant current charge/discharge galvanostatic measurements of a sample deposited at $10^{-2}$ mbar confirm that $700{ }^{\circ} \mathrm{C}$ is the optimal annealing temperature to maximize the normalized capacity $\left(65 \mu \mathrm{Ah} \cdot \mathrm{cm}^{-2} \cdot \mu \mathrm{m}^{-1}\right)$. 

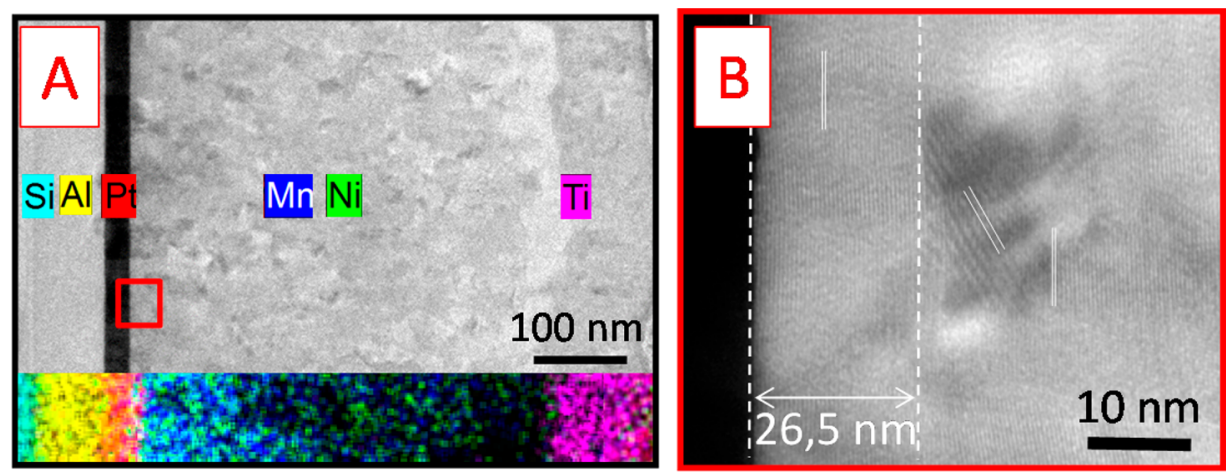

Figure 4. Transmission electron microscope analysis of the LMNO thin film deposited at $0.01 \mathrm{mbar}$ and annealed at $700{ }^{\circ} \mathrm{C}$. A. TEM analysis of the cross section $\mathrm{Si} / \mathrm{Al}_{2} \mathrm{O}_{3} / \mathrm{Pt} / \mathrm{LiMn}_{1.5} \mathrm{Ni}_{0.5} \mathrm{O}_{4} / \mathrm{Ti} / \mathrm{SiO}_{2}$ prepared by focus ion beam technique. This fracture analysis confirms the stacked layers, from $\mathrm{Al}_{2} \mathrm{O}_{3}$ insulating layer up to the $\mathrm{LMNO}$ thin films. The titanium and $\mathrm{SiO}_{2}$ coatings correspond to protective layers used for the film preparation by the focus ion beam technique. The chemical mapping analysis (EDS-STEM) of the cross section (Si turquoise blue, $\mathrm{Al}$ yellow, $\mathrm{Pt}$ red, $\mathrm{Mn}$ blue, $\mathrm{Ni}$ green, Ti pink) shown at the bottom of part A clearly confirms the absence of interdiffusion between the stacked layers. B. HRTEM image of the LMNO layer with a focus close to the Pt current collector in order to check the Pt/LMNO interface. From this analysis, the atomic plane seems to be well organized with a preferential orientation perpendicular to the substrate for the first $26.5 \mathrm{~nm}$ (out of plane analysis). Above this threshold, the LMNO exhibits a polycrystalline behavior.

Structural Characterization of LMNO Thin Films. A full structural characterization has been undertaken with three complementary techniques (transmission electron microscopy, X-ray diffraction, and Raman spectroscopy) enabling an imaging of the film at different scales, going from long-range (XRD) to a short one (TEM).

The TEM images reported in Figure 4 on a cross section obtained by the FIB technique (focused ion beam) shows the different stacked layers on silicon wafer where the thicknesses have been measured close to $85 \mathrm{~nm}$ for $\mathrm{Al}_{2} \mathrm{O}_{3}, 30 \mathrm{~nm}$ for the $\mathrm{Pt}$ current collector, and $480 \mathrm{~nm}$ for the LMNO positive electrode (Figure 4A). The chemical mapping analysis (EDS-STEM) has been performed on the cross section ( $\mathrm{Si}$ turquoise blue, $\mathrm{Al}$ yellow, Pt red, Mn blue, Ni green, Ti pink). It clearly confirms the absence of interdiffusion between the stacked layers: the $\mathrm{PtSi}$ alloy formation issue is no longer depicted and neither is any other diffusion from a layer to another, thus evidencing the pertinence of our layer stacking design. Another interesting point is observed in Figure 4B, where we can see that the LMNO layer exhibits a polycrystalline behavior with a different crystallized orientation (domains of about $20 \mathrm{~nm}$ ), except for a thickness of $26.5 \mathrm{~nm}$ along the Pt layer where a (111) preferred orientation is observed. To discriminate between epitaxial or fiber texture behavior, X-ray diffraction pole figure analysis has been performed. This study will be detailed in a following section depicting the influence of the thickness on electrochemical performance, but by anticipation, this first layer is a (111) fiber-textured one, not epitaxial.

$\mathrm{X}$-ray diffraction measurements were realized in BraggBrentano reflection configuration using Ni-filtered copper Kalpha radiation. In order to amplify the intensity of the LMNO layer, $2 \theta / \omega$ scans were done with a $\omega$ shift of $5^{\circ}$ to inhibit the signal issued from the silicon substrate. XRD patterns of LMNO thin films deposited at different pressures and annealed at $700{ }^{\circ} \mathrm{C}$ are displayed in Figure 5A,B. For the sake of clarity, two sets of diffractogramms (with intensity normalized to the (111) peak of $\mathrm{LMNO}$ at $18.8^{\circ}$ ) are reported with different sets of deposition pressure. For all the samples (Figure 5A,B), the main reflection peaks at $18.8^{\circ}, 36.4^{\circ}, 38.1^{\circ}, 44.3^{\circ}, 48.5^{\circ}, 58.8^{\circ}$, and $64.5^{\circ}$ are assigned to the LMNO spinel structure (JCPDS PDF 01-080-2162). The peak corresponding to the (111) diffraction plane of the platinum current collector (JCPDS PDF 00-004-0802) is observed at $40^{\circ}$, while the peak at $36^{\circ}$ (highlighted on the four XRD patterns) is also due to the (111) platinum layer, but to the $\mathrm{K}-\beta$ X-ray emission line that is not completely filtered. The crystallite size has been evaluated between 16 and $20 \mathrm{~nm}$ according to the Scherrer formula, whatever the pressure is. Moreover, at low pressure (Figure 5A), an additional $\mathrm{Li}_{2} \mathrm{MnO}_{3}$ phase (JCPDS PDF 00-027-1252) is depicted from the $(020)$ diffraction peak located at $21^{\circ}$. A preferential orientation is also observed according to the pressure. Indeed, since the entire patterns are normalized on the peak at $18.8^{\circ}$ ((111) diffraction plane), Figure 5A,B clearly shows an increase of the peak intensity at $44.3^{\circ}((400)$ diffraction plane) when the pressure increases from $6 \times 10^{-3}$ up to $9 \times 10^{-2}$ mbar. As a matter of fact, the $I_{(400)} / I_{(111)}$ ratio moves from 0.04 at low pressure to 2.83 at high pressure (i.e., a factor of 70 ). Except for this preferred orientation, all the diffractogramms of the four samples are similar. At this stage of the study, $\mathrm{Mn}-\mathrm{Ni}$ cation ordering/disordering on the LMNO spinel structure is suspected to have a significant influence on the electrochemical performance. However, with $\mathrm{Cu}$ based wavelength, it is impossible to distinguish using XRD the ordered spinel structures from the disordered one. Even if the space groups of the two polymorphs are different $\left(P_{3} 32\right.$ vs $F d \overline{3} m), \mathrm{Cu}$ XRD patterns are the same because scattering factors at the $\mathrm{Cu}$ edge are too close to be discriminant. To overcome this problem, Raman spectroscopy was used to further investigate these samples (Figure 5C,D).

At this stage of the structural analysis, a question is raised about knowing whether the deposition pressure directly influences the orientation of the thin film or if the change in deposition rate which is induced by the deposition pressure affects the orientation of the films. As shown in Figure 2, the deposition rate has been evaluated between 8 and $11 \mathrm{~nm} \cdot \mathrm{min}^{-1}$ depending on the deposition pressure. Consequently, the deposition time has been tuned for the four samples being tested to have the same thickness as depicted on the SEM cross sections of Figure 1. To the author's knowledge, deposition pressure is responsible for the densification of sputtered thin films owing to the high energy of the condensed species within the plasma, (atomic peening effect). At low pressure, high 

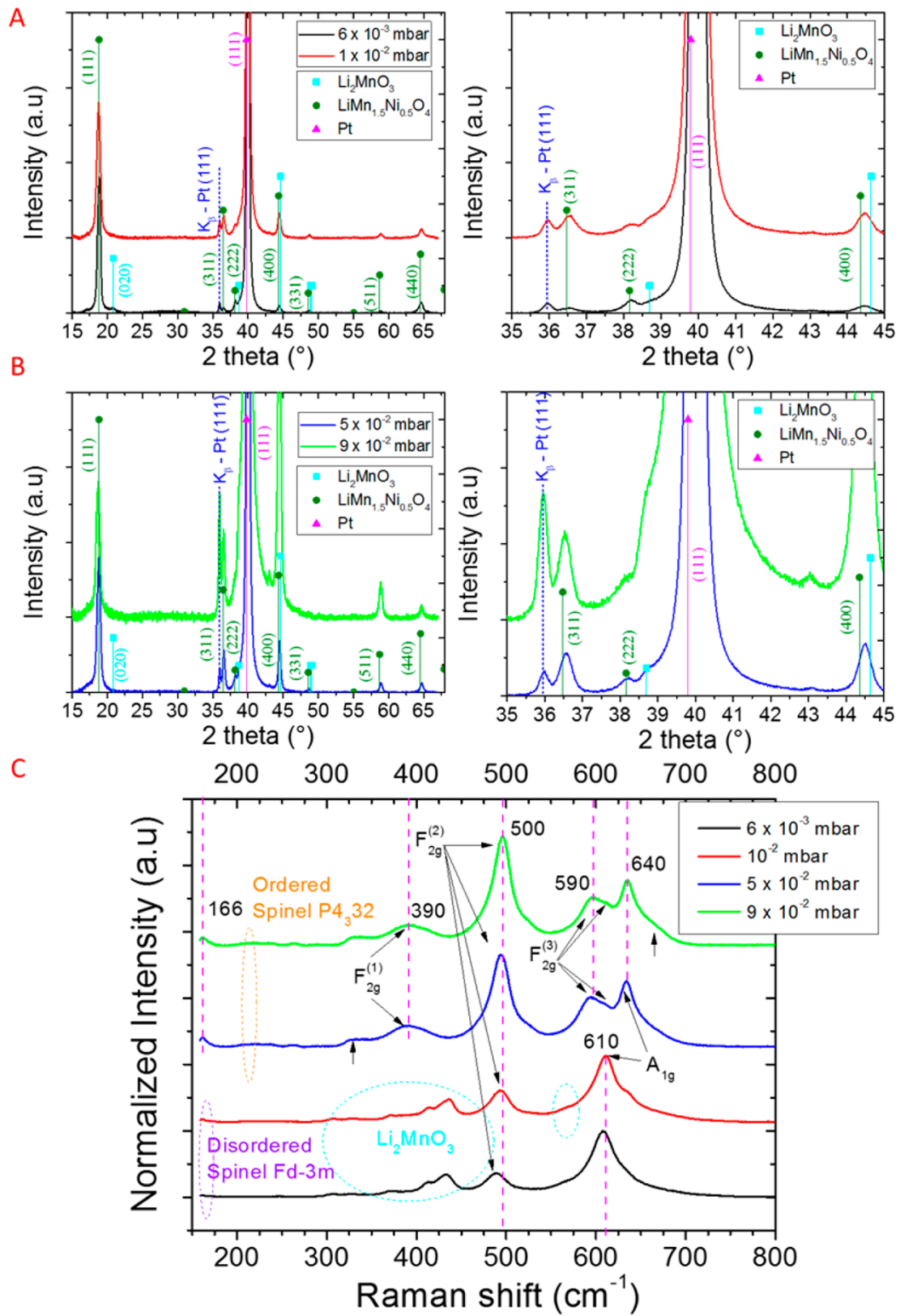

D

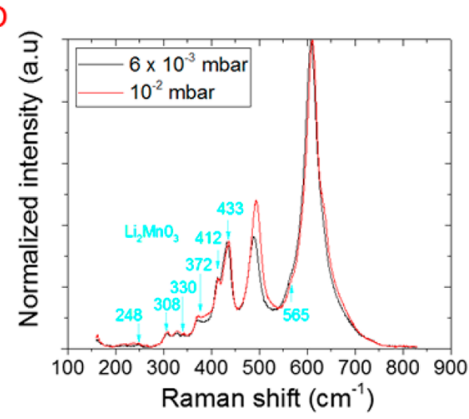

E

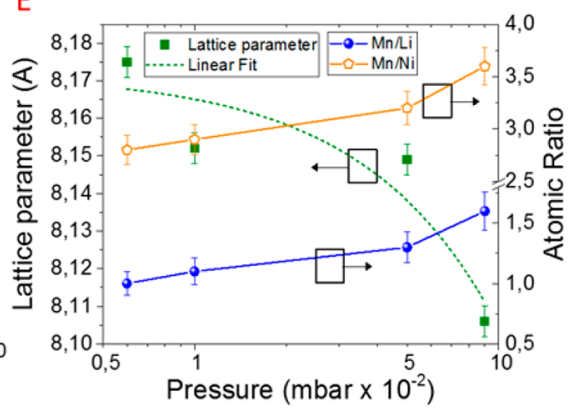

Figure 5. Structural analyses of the sputtered thin films deposited at 4 different pressures and annealed at $700{ }^{\circ} \mathrm{C}$. A. XRD analysis of the low pressure $\mathrm{Al}_{2} \mathrm{O}_{3} / \mathrm{Pt} / \mathrm{LMNO}$ deposited samples $\left(6 \times 10^{-3}\right.$ and $\left.10^{-2} \mathrm{mbar}\right)$. An inset of the diffractogramm is proposed between 35 and $45^{\circ}$. $\mathrm{B}$. XRD analysis of the $\mathrm{Al}_{2} \mathrm{O}_{3} / \mathrm{Pt} / \mathrm{LMNO}$ samples deposited at higher pressure $\left(5 \times 10^{-2}\right.$ and $\left.9 \times 10^{-2} \mathrm{mbar}\right)$. An inset of the diffractogramm is proposed between 35 and $45^{\circ}$. C. Raman spectra of the thin films. Clearly, the Raman analysis confirms that the deposition pressure influences the atomic ordering within the studied positive electrode material: the disordered spinel $F d \overline{3} m$ is obtained at low pressure while the ordered spinel $P 4_{3} 32$ is synthesized at high pressure. D. Raman spectra of the low pressure samples $(0.006$ and $0.01 \mathrm{mbar})$ demonstrates the presence of the $\mathrm{Li}_{2} \mathrm{MnO}_{3}$ monoclinic phase. E. Evolution of the lattice parameter and atomic ratio regarding the deposition pressure.

energy atoms strike the film surface under growth and induce atomic resputtering in the column boundaries leading to dense thin films. Competitive growth between several lattice planes occurs during the sputtering deposition of LMNO layers, and 

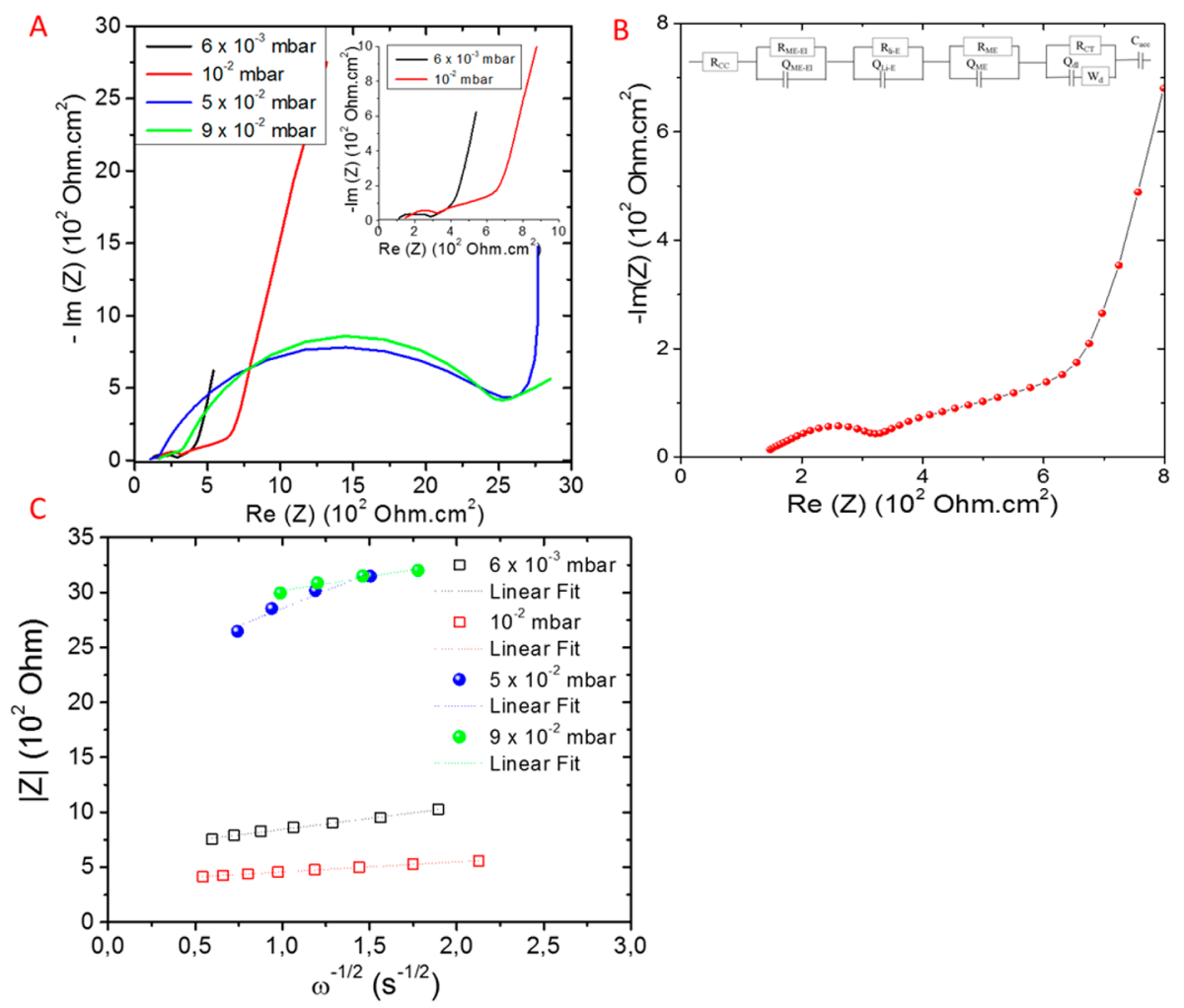

Figure 6. A. Nyquist spectra of the sputtered thin films recorded between $100 \mathrm{kHz}$ and $5 \mathrm{mHz}$. B. Focus on the sample deposited at $10^{-2} \mathrm{mbar}$ is proposed as well as an equivalent circuit used to fit the corresponding Nyquist plot. C. Plots of the Warburg impedance as a function of the inverse square root of the angular frequency for the four thin films under test.

pressure directly changes the orientation of the thin films as shown on the diffractogramms reported in Figure 5.

Indeed, since Raman spectroscopy clearly enables distinguishing between $\mathrm{Mn}-\mathrm{O}$ bonds and $\mathrm{Ni}-\mathrm{O}$ ones, it has been used to identify which polymorph of the spinel phases has been formed. First, all the Raman peak intensities are higher in an ordered spinel (hereafter denoted by its space group, i.e., $P_{3} 32$ ) than in a desordered one (space group $F d \overline{3} m$ ). Moreover, it is known ${ }^{7,40}$ that an increase in the Raman peak intensity corresponding to the $\mathrm{Ni}-\mathrm{O}$ band $\left(166\right.$ and $\left.410 \mathrm{~cm}^{-1}\right)$ occurs with ordering $\left(\mathrm{P}_{3} 32\right)$, i.e., at high pressure (Figure $5 \mathrm{C}$ ), while samples deposited at low pressure correspond to the disordered spinel structures $(F d \overline{3} m)$. The Raman spectra of the four samples under test clearly evidence the $A_{1 g}, F_{2 g}{ }^{(1)}, F_{2 g}{ }^{(2)}$, and $\mathrm{F}_{2 \mathrm{~g}}{ }^{(3)}$ peaks assigned to the vibration modes of a cubic spinel type structure. ${ }^{41}$ Nevertheless, a slight shift of these modes is visible as a function of the pressure. Those shifts have already been observed when a comparison is done between disordered vs ordered spinel compounds. ${ }^{40,42}$

From the Raman spectra of the low pressure samples (Figure $5 \mathrm{D})$, the presence of an additional $\mathrm{Li}_{2} \mathrm{MnO}_{3}$ phase is confirmed by a set of seven peaks assigned ${ }^{43}$ to the phonon vibrations $\left(248,308,330,372,412,433\right.$, and $\left.565 \mathrm{~cm}^{-1}\right)$.

The lattice parameters of LMNO (Figure 5E) issued from Rietveld refinement are found to decrease from 8.167 down to $8.105 \AA$ when the deposition pressure increases. This last conclusion has a significant importance as it is known $^{7}$ that disordered spinel LMNO structures have a larger volume cell than the ordered spinel LMNO one. In such a way, the $F d \overline{3} m$ disordered spinel LMNO phase seems to be formed at low pressure while a $\mathrm{P}_{3} 32$ ordered one is obtained at higher pressure, which corroborates the conclusion issued from Raman analysis. However, according to ref 44, nanodomains of ordered or disordered spinel can occur in our LMNO thin films and we cannot exclude a fraction of the ordered phase in a disordered matrix and vice versa.

The atomic ratio $\mathrm{Mn} / \mathrm{Ni}$ and $\mathrm{Mn} / \mathrm{Li}$ are found to increase when the deposition pressure increases from $6 \times 10^{-3}$ to $9 \times$ $10^{-2}$ mbar (Figure 5E).

Electrochemical Characterizations of the LMNO Thin Films. In order to have a better understanding of the diffusion process of the lithium ion in thin film LMNO electrodes, an electrochemical impedance spectroscopy (EIS) study was undertaken on the four samples with different deposition pressures. For each sample, EIS has been performed between $100 \mathrm{kHz}$ and $5 \mathrm{mHz}$ at $4.6 \mathrm{~V}$ vs $\left(\mathrm{Li} / \mathrm{Li}^{+}\right)$after $10 \mathrm{CV}$ cycles. Such a frequency range is restricted between $500 \mathrm{~Hz}$ and 5 $\mathrm{mHz}$ to plot the evolution of the Warburg impedance as a function of angular frequency in the linear region. Nyquist plots are represented in Figure 6A. Again, clear differences can be noticed between low and high pressures. Disordered spinel exhibits faster kinetics than the ordered one with an area specific resistance (ASR) contribution of 200,600, 2500, and $2400 \mathrm{Ohm} \cdot \mathrm{cm}^{2}$ for the $6 \times 10^{-3}, 10^{-2}, 5 \times 10^{-2}$, and $9 \times 10^{-2}$ mbar samples, respectively. The ASR obtained for the disordered spinel is comparable to the value reported by the Dudney $^{12}$ et al. and Mohamedi ${ }^{6}$ et al. groups. All plots have been fitted according to the equivalent circuit proposed in Figure 6B. This model inspired from previous works ${ }^{45}$ consists of (i) an electrolyte bulk resistance, (ii) a capacitance and resistance coming from the electrolyte, (iii) the Li/electrolyte interface, (iv) the LMNO films (charge transfer resistance coupled with a double layer capacitance of the electrolyte/ LMNO interface, (v) a Warburg impedance coming from the 
A
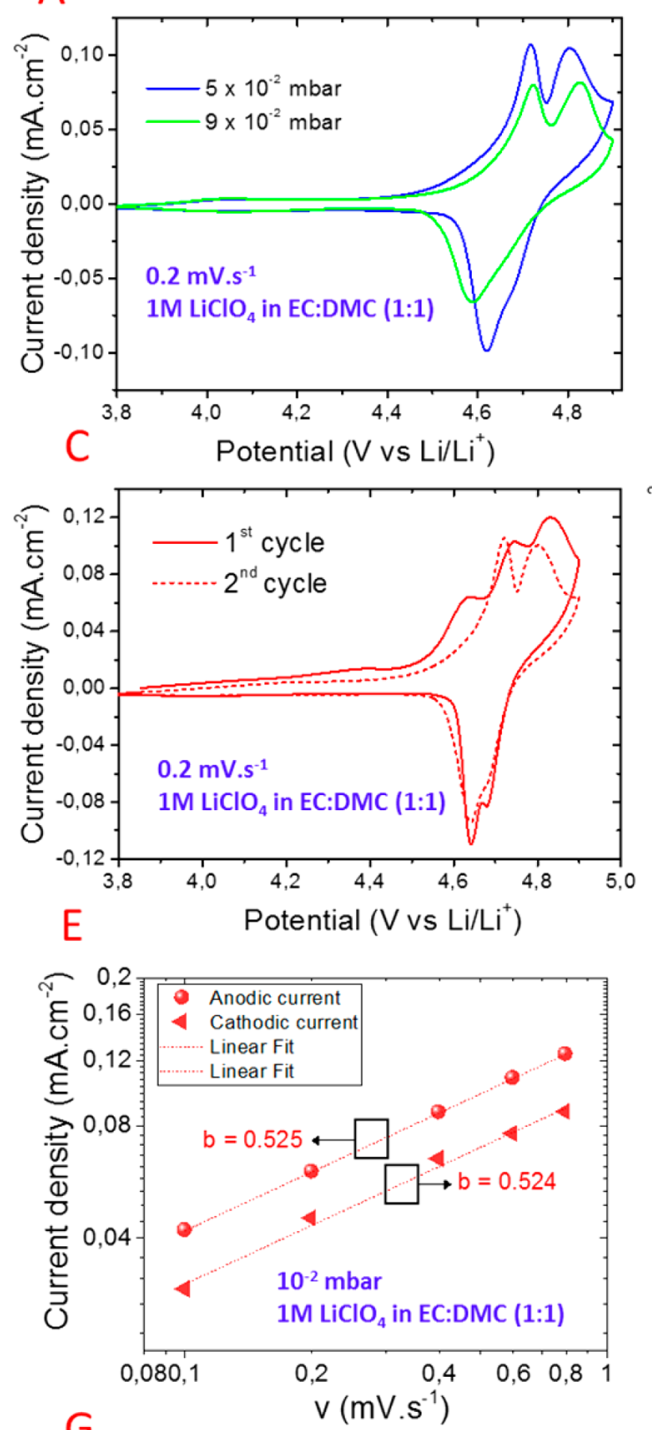

G

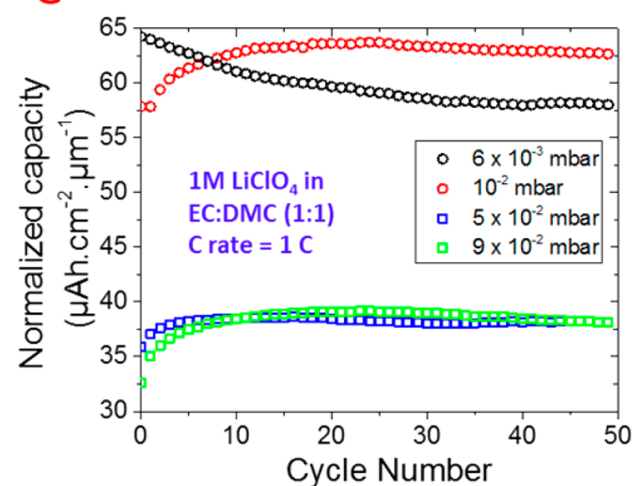

B
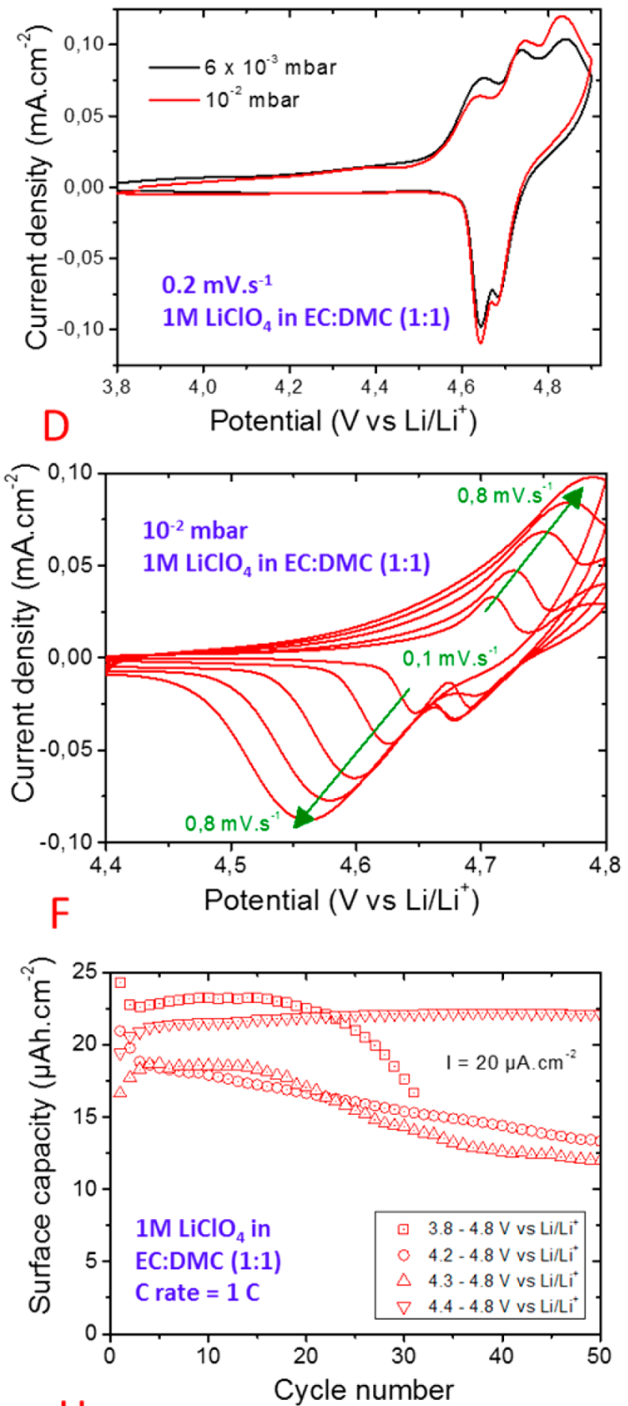

$\mathrm{H}$

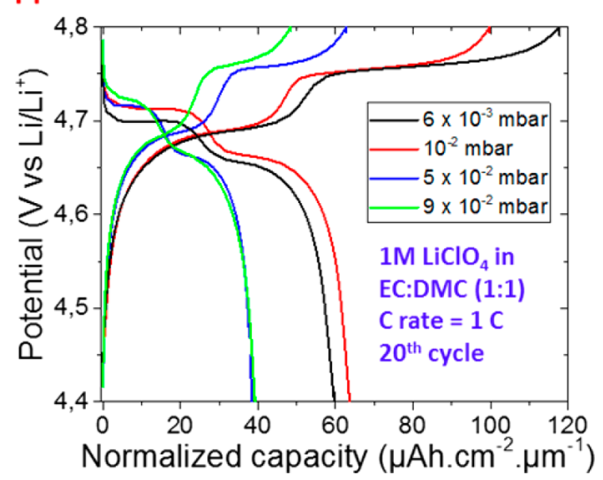

Figure 7. Electrochemical analysis of the sputtered $\mathrm{LiMn}_{1.5} \mathrm{Ni}_{0.5} \mathrm{O}_{4}$ thin films as a function of the deposition pressure. All the layers are annealed at $700{ }^{\circ} \mathrm{C}$ under air atmosphere during $2 \mathrm{~h}$. A specific color, depending on the deposition pressure, is applied for each sample on all the reported graphs from A to $\mathrm{H}$. The electrolyte is $1 \mathrm{M} \mathrm{LiClO}_{4}$ in EC/DMC (1/1). A, B. Cyclic voltammogram (CV) of the four tested samples (first cycle) as a function of the deposition pressure between 3.8 to $4.9 \mathrm{~V} \mathrm{vs} \mathrm{Li} / \mathrm{Li}^{+}$. The sweep rate is fixed at $0.2 \mathrm{mV} \cdot \mathrm{s}^{-1}$. C. CV of the sample deposited at $10^{-2}$ mbar: comparison between the first and the second cycles. D. Cyclic voltammograms of the LMNO thin film deposited at $10^{-2} \mathrm{mbar}$ as a function of the sweep rate $(0.1$ up to $0.8 \mathrm{mV} / \mathrm{s})$. E. Evolution of the anodic and cathodic peak current regarding the square root of the sweep rate illustrating that the lithium transport within the layer is diffusion controlled $(b=0.52)$. F. Evolution of the surface capacity as a function of the working electrochemical window. G. Galvanostatic plots of all the tested samples between 4.4 and $4.8 \mathrm{~V} \mathrm{vs} \mathrm{Li} / \mathrm{Li}^{+}$at $1 \mathrm{C}$. The specific capacity is normalized to the layer thickness to have a good comparison between the tested samples. H. Evolution of the potential as a function of the normalized charge/ discharge capacity for the four tested pressures (20th cycle). On those galvanostatic plots, each sample clearly exhibits two plateaus occurring during the oxidation (4.68 and $4.75 \mathrm{~V}$ vs $\mathrm{Li} / \mathrm{Li}^{+}$) process and two plateaus occurring during the reduction process $\left(4.65\right.$ and $\left.4.72 \mathrm{Vvs} \mathrm{Li} / \mathrm{Li}^{+}\right)$. 
diffusion the electroactive species, and (vi) an accumulation capacitance describing lithium accumulation at very low frequencies.

Under semi-infinite conditions, the apparent chemical diffusion coefficient of the lithium ion $\left(D_{\text {app }}\right)$ can be calculated from the Warburg impedance analysis ${ }^{46}$ which is expressed in the complex plane using

$$
Z_{\mathrm{w}}=\sigma(1-j) \omega^{-0.5}=\frac{V_{\mathrm{m}}}{A F n \sqrt{2 D_{\mathrm{app}}}} \frac{\mathrm{d} E}{\mathrm{~d} x}(1-j) \omega^{-0.5}
$$

where $V_{\mathrm{m}}$ is the molar volume of the LMNO, $F$ the Faraday constant, $n$ the charge transfer number, $A$ the surface area of the film, $E$ the potential, and $x$ the lithium concentration. Finally, after a series of equation transformations, $\sigma$ can be expressed ${ }^{6}$ as

$$
\sigma=\frac{Q_{l} M l}{n F C_{\text {acc }} \sqrt{2 D_{\text {app }}}}
$$

where $Q_{i}$ is the capacity of the LMNO layer $\left(147 \mathrm{mAh} \cdot \mathrm{g}^{-1}\right), M$ the molecular weight of LMNO $\left(183 \mathrm{~g} \cdot \mathrm{mol}^{-1}\right), l$ the diffusion pathway (corresponding to the film thickness), and $C_{\text {acc }}$ the accumulation capacitance obtained with the fitting procedure. $\sigma$ (ionic conductivity) can be obtained from the slope of the Warburg impedance as a function of the square root of the angular frequency (Figure 6C). After calculation, the apparent diffusion coefficient $D_{\text {app }}$ is found close to $2 \times 10^{-10} \mathrm{~cm}^{2} \cdot \mathrm{s}^{-1}$ for the disordered spinel and $3 \times 10^{-11} \mathrm{~cm}^{2} \cdot \mathrm{s}^{-1}$ for the ordered one, almost 1 order of magnitude more, which reflects the resulting kinetics. Note that, at this potential, these values are in good agreement with those reported by $\mathrm{Xia}^{9,10}$ et al. and Mohamedi ${ }^{6}$ et al., using the same calculations.

The electrochemical analysis of the sputtered LMNO as a function of the operating pressure is displayed in Figure 7. Cyclic voltammetry $(\mathrm{CV})$ is first performed on the four samples at a scan rate of $0.2 \mathrm{mV} \cdot \mathrm{s}^{-1}$ in $1 \mathrm{M} \mathrm{LiClO}_{4}$ in $\mathrm{EC} / \mathrm{DMC}(1 / 1)$ between 3.8 and $4.9 \mathrm{~V}$ vs $\mathrm{Li} / \mathrm{Li}^{+}$. In Figure $7 \mathrm{~A}, \mathrm{~B}$, a small redox peak due to the $\mathrm{Mn}^{3+} / \mathrm{Mn}^{4+}$ redox couple is detected, thus highlighting the presence of a small amount of $\mathrm{Mn}^{3+}$ in the sample, whatever the pressure is. This redox activity is generally attributed to oxygen deficiency in the films owing to the high temperature of the post deposition annealing. Indeed, to compensate the oxygen deficiency, a small amount of $\mathrm{Mn}^{4+}$ is reduced to $\mathrm{Mn}^{3+}$. Similar results have been observed previously on bulk or thin film LMNO electrodes. ${ }^{1,9,10}$ In Figure $7 \mathrm{~A}$, only two oxidation peaks at high potential ( 4.7 and $4.8 \mathrm{~V}$ ) are depicted during the first cycle demonstrating the change of the oxidation state of the Nickel element (from $\mathrm{Ni}^{2+}$ to $\mathrm{Ni}^{3+}$ and $\mathrm{Ni}^{3+}$ to $\left.\mathrm{Ni}^{4+}\right)$. Only one large peak $\left(4.6 \mathrm{~V}\right.$ vs $\left.\mathrm{Li} / \mathrm{Li}^{+}\right)$with a small shoulder is visible during the reduction process which is characteristic of ordered LMNO spinel ${ }^{42}$ where the double peaks are closer than in the disordered spinel.

In Figure 7B, two sets of redox peaks (4.72/4.82 V and 4.65/ $4.7 \mathrm{~V}$ vs $\mathrm{Li} / \mathrm{Li}^{+}$) have been found at low deposition pressure during the first cycle, thus indicating the redox activity of the nickel $\left(\mathrm{Ni}^{2+} / \mathrm{Ni}^{3+}\right.$ and $\left.\mathrm{Ni}^{3+} / \mathrm{Ni}^{4+}\right)$ in the LMNO film. An oxidation peak is depicted at $4.6 \mathrm{~V}$ vs $\mathrm{Li} / \mathrm{Li}^{+}$only at low deposition pressure and is attributed to the presence of $\mathrm{Li}_{2} \mathrm{MnO}_{3}$ additional phase already observed by XRD and Raman analyses and occurring only for disordered spinel phase (low deposition pressure). As no reduction peak is observed in the similar region, this oxidation reaction is irreversible. When the pressure is increased, the oxidation peaks attributed to the nickel element are shifted toward higher potentials while reduction peaks shift toward lower potentials, thus indicating that the deposition pressure is a crucial parameter to stabilize the initial oxidation state of the nickel element. During the second cycle (Figure $7 \mathrm{C}$ ), the oxidation peak at $4.6 \mathrm{~V}$ vs $\mathrm{Li} / \mathrm{Li}^{+}$ is no longer observed, indicating that the $\mathrm{Li}_{2} \mathrm{MnO}_{3}$ additional phase only exhibits electrochemical activity during the first cycle.

Cyclic voltammetry at different sweep rates has been used to check the lithium transport within the LMNO thin film deposited at $10^{-2}$ mbar (Figure 7D). Not surprisingly, the peak current is linearly proportional to the square root of the sweep rate indicating that the lithium transport is under diffusion control (Figure 7E). The $b$-coefficient issued from the power law $\left(I=a \nu^{b}\right.$, where $a$ and $b$ are arbitrary coefficients and $\nu$ is the sweep rate in $\mathrm{mV} \cdot \mathrm{s}^{-1}$ ) is equal to $0.524 \pm 0.100$ for anodic and cathodic currents meaning that the stored charge within the LMNO layer arises from a semi-infinite diffusion process.

Galvanostatic measurements were also performed on these samples. The first goal was to determine the suitable electrochemical window providing a stable cycling behavior of the LMNO thin films. When the samples are cycled between 3.8 and $4.8 \mathrm{~V}$ vs $\mathrm{Li} / \mathrm{Li}^{+}$a small plateau is observed at $4.2 \mathrm{~V}$ vs $\mathrm{Li} / \mathrm{Li}^{+}$typically assigned to the $\mathrm{Mn}^{3+} / \mathrm{Mn}^{4+}$ redox couple., ${ }^{7,9}$ The small amount of $\mathrm{Mn}^{3+}$ within the LMNO thin film is disproportionated when cycling in liquid electrolyte leading to the formation of $\mathrm{Mn}^{2+}$ and $\mathrm{Mn}^{4+}$ cations that is accompanied by the loss of soluble $\mathrm{Li}_{2} \mathrm{O}$ and $\mathrm{MnO}$ into the solution. ${ }^{10}$ This behavior was typically observed for thin films deposited by PLD or RF sputtering where oxygen loss could occur during the vacuum deposition process or during the high temperature annealing step. ${ }^{10}$ For the stoichiometric $\mathrm{LiMn}_{1.5} \mathrm{Ni}_{0.5} \mathrm{O}_{4}$ layer, the manganese is at a +4 oxidation state while the nickel is at +2 . The surface discharge capacity of the sample deposited at $10^{-2} \mathrm{mbar}$ (Figure 7F) is found to be close to $22 \mu \mathrm{Ah} \cdot \mathrm{cm}^{-2}$ at $1 \mathrm{C}$, but this capacity quickly fades from the 20th cycle.

When the electrochemical window is reduced progressively from $3.8-4.8$ to $4.4-4.8 \mathrm{~V}$ vs $\mathrm{Li} / \mathrm{Li}^{+}$, the discharge capacity at $1 \mathrm{C}$ exhibits a good cycling behavior during the first 50 cycles and reaches $21 \mu \mathrm{Ah} \cdot \mathrm{cm}^{-2}$. The evolution of the normalized capacity (in $\mu \mathrm{Ah} \cdot \mathrm{cm}^{-2} \cdot \mu \mathrm{m}^{-1}$ ) within $4.4-4.8 \mathrm{~V}$ vs $\mathrm{Li} / \mathrm{Li}^{+}$is reported in Figure $7 \mathrm{G}$ for the four samples under test at $1 \mathrm{C}$. On this figure, two different behaviors regarding the operating pressure are observed again. The low-deposition samples exhibit the highest normalized capacity close to the theoretical one $\left(66 \mu \mathrm{Ah} \cdot \mathrm{cm}^{-2} \cdot \mu \mathrm{m}^{-1}\right.$ taking into account a bulk density of $4.5 \mathrm{~g} \cdot \mathrm{cm}^{-3}$ and a gravimetric capacity of $\left.147 \mathrm{mAh} \cdot \mathrm{g}^{-1}\right)$. Nevertheless, the retention capacity seems to be better for the sample deposited at $10^{-2} \mathrm{mbar}$ as compared to the one deposited at $6 \times 10^{-3} \mathrm{mbar}$. The capacity reached by the two samples deposited at higher pressure is equal to $40 \mu \mathrm{Ah}$. $\mathrm{cm}^{-2} \cdot \mu \mathrm{m}^{-1}$ demonstrating the superior performance of the disordered spinel as compared to the ordered one. Figure $7 \mathrm{H}$ depicts the evolution of the potential as a function of the normalized capacity at the 20th cycle (1C rate) which clearly illustrates the redox activities of the nickel $\left(\mathrm{Ni}^{2+} / \mathrm{Ni}^{3+}\right.$ and $\mathrm{Ni}^{3+} /$ $\mathrm{Ni}^{4+}$ ) within the LMNO thin films at different pressures. The charge capacity is higher than the discharge one for all the samples. The irreversible capacity is never whittled down to zero, which can be attributed to a continuous electrolyte decomposition over $4.3 \mathrm{~V}$ vs $\left(\mathrm{Li} / \mathrm{Li}^{+}\right)$during cycling. At such high voltage, unwanted electrolyte oxidation occurs with standard liquid electrolytes leading to the decomposition of 

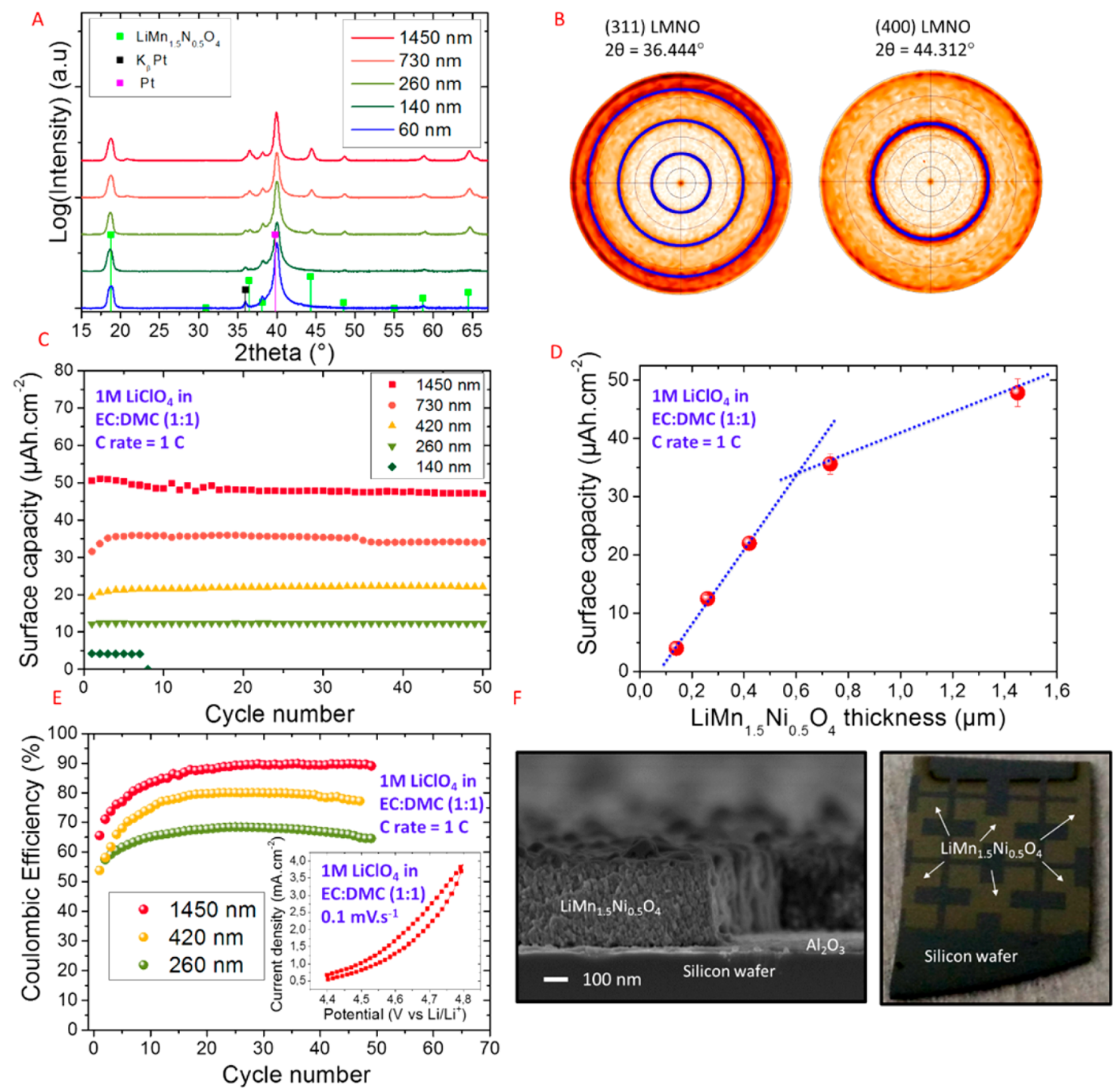

Figure 8. Evolution of the LMNO performance as a function of the layer thickness. A. Bragg-Brentano X-ray diffraction analysis (all diffractogramms are normalized to the 111 peak of LMNO at $\sim 18^{\circ}$ ). B. X-ray in-plane pole figures on peaks (311) and (400) of the LMNO thin film. Rings (modeled by Stereopole in blue) are systematically observed, indicating a fiber texture rather than an epitaxy. C and D. Evolution of the surface capicity vs cycle number and as a function of the film thickness. E. Enhancement of the Coulombic efficiency during the first 50 cycles. The inset of the Figure $8 \mathrm{E}$ reports the cyclovoltammogram (second cycle) of the $\mathrm{Si} / \mathrm{Al}_{2} \mathrm{O}_{3} / \mathrm{Pt}$ stacked layers at $0.1 \mathrm{mV} \cdot \mathrm{s}^{-1}$ between 4.4 and $4.8 \mathrm{~V}$ vs Li/ $\mathrm{Li}^{+}$. F. Patterning of the $\mathrm{LiMn}_{1.5} \mathrm{Ni}_{0.5} \mathrm{O}_{4}$ thin films (as clover shape) achieved by using a dry etching (plasma) process compatible with microelectronic fabrication facilities: an SEM fracture analysis and a tilted optical view are reported.

inorganic compounds such as lithium salt and organic solvent. ${ }^{2}$ These decomposed products form a layer at the electrode surface acting as a solid electrolyte interphase (SEI). Consequently, low Coulombic efficiency is generally obtained for such a high voltage electrode with conventional liquid electrolyte. In our case, for the four films under test, the Coulombic efficiency is measured close to $75 \%$ (with a $400 \mathrm{~nm}$ layer), in good agreement with results reported by the group of Dudney. ${ }^{12}$ To understand this relatively bad efficiency, one has to come back to the Coulombic efficiency definition, i.e., $Q_{\text {discharge }} /\left(Q_{\text {charge }}+Q_{\text {SEI }}\right)$. On one hand, for bulk electrodes (powder or thick layer), the amount of active material is high $\left(>10 \mathrm{mg} \cdot \mathrm{cm}^{-2}\right)$ and the thickness $(20 \mathrm{~nm})$ of the SEI (and hence its negative contribution) is negligible as compared to the thickness of the active layer $(>100 \mu \mathrm{m})$. On the other hand, for the thin film $(0.5 \mu \mathrm{m}$ thick $)$, the amount of active materials is low $\left(0.2 \mathrm{mg} \cdot \mathrm{cm}^{-2}\right)$, and its thickness has a strong influence onto the Coulombic efficiency: low Coulombic efficiency (75\%) has been reported by Dudney et al. for $500 \mathrm{~nm}$-thick
LMNOs while the $2-\mu \mathrm{m}$ LMNO layer exhibits a Coulombic efficiency ${ }^{13}$ higher than $98 \%$. In our study, for the sample deposited at $10^{-2} \mathrm{mbar}$ (the best compromise between capacity retention and performance) the Coulombic efficiency is $70 \%$ for $0.4-\mu \mathrm{m}$ thick LMNO which is low for long-term application. A simple way to increase the Coulombic efficiency is thus to increase the thickness of the active material.

Figure 8 reports the behavior of the films deposited at $10^{-2}$ mbar as a function of the film thickness. Six different thicknesses have been tested from 60 to $1450 \mathrm{~nm}$. For the sake of clarity, the diffractogramm of the $0.4 \mu \mathrm{m}$ thick LMNO (already given in Figure 5A,B, red curve) is not reported again in Figure 8A. Two important facts have to be noted on XRD analysis: (i) for the thinnest film, only (111) and (222) peaks are clearly visible, and (ii) with increasing thickness, all the intensities of other peaks are increasing without any index dependence (as a classical powder). These two observations are in good agreement with the previous TEM study where, at this 
pressure, a fully (111)-oriented deposition is observed on the first $25 \mathrm{~nm}$ of the LMNO layer.

At this stage, both XRD and TEM results converge to an orientation in the direction perpendicular to the silicon wafer, but there is no information about the in plane orientation. Indeed, either the film is randomly distributed in the horizontal direction (giving rise to a so-called fiber texture), or it is also oriented (giving rise to a so-called epitaxial growth). To answer this question, XRD pole figures were recorded on (311) and (400) peaks of the LNMO $60 \mathrm{~nm}$-thin film (Figure 8B). In this pole figure, strong peaks that would represent single-crystal-like texture (i.e., epitaxy) are absent, whereas continuous rings are observed, indicating a random in-plane orientation of the grains in the film. The different observed rings have been unambiguously modeled (blue rings) with the software Stereopole, ${ }^{47}$ and we can conclude the presence of a (111) fiber-textured LMNO thin film on a (100) Si substrate.

The surface capacity, measured between 4.4 and $4.8 \mathrm{~V}$ vs $\mathrm{Li} /$ $\mathrm{Li}^{+}$at $1 \mathrm{C}$, is presented in Figure $8 \mathrm{C}$ as a function of cycle number. The $60 \mathrm{~nm}$-thick LMNO film does not provide any capacity while the capacity of the $140 \mathrm{~nm}$-thick quickly fades at the seventh cycle. This behavior can be attributed to the preferred orientation observed in the film, orientation that would be detrimental and very sensitive for low thickness where this effect is predominant. ${ }^{48}$ As soon as the film thickness is higher than $260 \mathrm{~nm}$, the capacity retention of the LMNO films is stabilized over at least the first 50 cycles. Not surprisingly, the surface capacity increases with the thickness. As shown in Figure $8 \mathrm{D}$, the surface capacity, measured at $1 \mathrm{C}$, does not vary linearly with the thickness and seems to saturate when the thickness is higher than $0.6 \mu \mathrm{m}$. The evolution of the Coulombic efficiency (CE) as a function of the cycle number is presented in Figure $8 \mathrm{E}$. The surface capacity due to electrolyte decomposition and SEI contribution is evaluated close to $5 \mu \mathrm{Ah} \cdot \mathrm{cm}^{-2}$ based on the CV reported in the inset of the Figure $8 \mathrm{E}$. Regarding the formula used to calculate the Coulombic efficiency ${ }^{13}$ for thin film electrodes $\left(\mathrm{CE}=Q_{\text {discharge }} /\right.$ $\left.\left(Q_{\text {charge }}+Q_{\text {cell }}+Q_{S E I}\right)\right)$, the contribution of $Q_{\text {cell }}+Q_{S E I}$ is 5 $\mu \mathrm{Ah} \cdot \mathrm{cm}^{-2}$. For $450 \mathrm{~nm}$-thick LMNO thin films exhibiting 20 $\mu \mathrm{Ah} \cdot \mathrm{cm}^{-2}$ surface capacity (Figure $8 \mathrm{C}$ ) at the 30th cycle, such capacity is not negligible and $\mathrm{CE}=20 /(20+5)=80 \%$ (Figure $8 \mathrm{E})$. For the thinner film $(260 \mathrm{~nm}$ thick $), \mathrm{CE}=(12 /(12+5)=$ $70 \%$, and for thicker film $(1450 \mathrm{~nm}), \mathrm{CE}=48 /(48+5)=91 \%$. Consequently, the Coulombic efficiency (CE) is degraded due to decomposition of the electrolyte and SEI contribution. CE is demonstrated to be thickness-dependent for thin film electrodes. Finally, as demonstrated in Figure 8F, we successfully pattern the LMNO thin films with a standard plasma etching process $\left(\mathrm{Cl}_{2} / \mathrm{Ar}\right.$ reactive ion etching process $)$ available in the microelectronic industry which paves the way toward the fabrication of full cell Li-ion microbattery using CMOS compatible equipment. The process is found to be used for mass production. No physical mask has been used to achieve the patterning (only a photoresist layer spin coated on the top the $\mathrm{LiMn}_{1.5} \mathrm{Ni}_{0.5} \mathrm{O}_{4}$ layer is proposed as an etching mask).

This study clearly shows that a careful control of the sputtering deposition parameters and annealing conditions is fundamental to understand the local ordering of the nickel and manganese atoms in the $\mathrm{LiMn}_{1.5} \mathrm{Ni}_{0.5} \mathrm{O}_{4}$ spinel structure. Such local ordering has been shown to induce a significant contribution to the electrochemical properties of LMNO thin films. A similar conclusion dealing with the structuralelectrochemical properties relationship has already been reported $^{44}$ on the powder based electrode. Moreover, we have shown that deposition pressure higher than $10^{-2} \mathrm{mbar}$ combined with a $2 \mathrm{~h}$-annealing step at $700{ }^{\circ} \mathrm{C}$ allows to limit the presence of an additional phase such as $\mathrm{Li}_{2} \mathrm{MnO}_{3}$.

\section{CONCLUSION}

To summarize, we have first solved the technological issue of the PtSi phase which originates from the diffusion of Si through the Cr layer to form the PtSi phase under annealing treatment, damaging the current collector. The proposed solution is to substitute the $\mathrm{Cr}$ layer by a very dense and pinhole free $\mathrm{Al}_{2} \mathrm{O}_{3}$ thin film deposited by ALD acting as a barrier diffusion. This $\mathrm{Al}_{2} \mathrm{O}_{3} / \mathrm{Pt}$ stacked layers operating as a functional current collector for high potential positive electrode material are compatible with the fabrication process of the $3 \mathrm{D}$ microbattery, ${ }^{35,49}$ where a careful control of the 3D deposition process and annealing step has to be taken into account to promote the crystallization of the positive electrode thin film without inducing the formation of any additional phase and interdiffusion between each layer. In this manuscript, we report a full investigation of RF-sputtered LMNO thin films as a function of the deposition pressure and the film thickness. We have demonstrated that the pressure parameter plays a key role on the $\mathrm{Mn}-\mathrm{Ni}$ cations ordering in spinel-like structures and consequently on the electrochemical performance. We have thus shown that LMNO thin films deposited at $10^{-2}$ mbar and annealed at $700{ }^{\circ} \mathrm{C}$ deliver a normalized capacity of $65 \mu \mathrm{Ah}$. $\mathrm{cm}^{-2} \cdot \mu \mathrm{m}^{-1}$ with good capacity retention upon cycling thanks to their disordered spinel structure. A kinetic study performed with CV and EIS measurements confirms these performances, since the samples deposited at low deposition pressure (disordered spinel) exhibit the highest chemical diffusion coefficient as compared to the ordered one. We have also demonstrated a significant dependence of the Coulombic efficiency with the thickness for high voltage LMNO thin film electrodes. This work is, to our knowledge, the most complete study combining structural and electrochemical characterizations of LMNO thin film obtained by the RF sputter deposition process.

\section{AUTHOR INFORMATION}

\section{Corresponding Authors}

*(P.R.) E-mail: pascal.roussel@ensc-lille.fr.

*(C.L.) E-mail: christophe.lethien@iemn.univ-lille1.fr. ORCID

Christophe Lethien: 0000-0001-8906-8308

\section{Notes}

The authors declare no competing financial interest.

\section{ACKNOWLEDGMENTS}

The authors also want to thank the French network on electrochemical energy storage (RS2E) for the financial support. The French RENATECH network is greatly acknowledged for the use of microfabrication facilities. Chevreul Institute (FR 2638), Ministère de l'Enseignement Supérieur et de la Recherche, Région Hauts de France, and FEDER are acknowledged for supporting and funding TEM and XRD facilities. 


\section{REFERENCES}

(1) Manthiram, A.; Chemelewski, K.; Lee, E.-S. A Perspective on the High-Voltage LiMn1.5Ni0.5O4 Spinel Cathode for Lithium-Ion Batteries. Energy Environ. Sci. 2014, 7, 1339-1350.

(2) Aurbach, D. Review of Selected Electrode-solution Interactions Which Determine the Performance of Li and Li Ion Batteries. J. Power Sources 2000, 89, 206-218.

(3) Mahieu, S.; Ghekiere, P.; De Winter, G.; De Gryse, R.; Depla, D.; Van Tendeloo, G.; Lebedev, O. I. Biaxially Aligned Titanium Nitride Thin Films Deposited by Reactive Unbalanced Magnetron Sputtering. Surf. Coat. Technol. 2006, 200, 2764-2768.

(4) Freixas, J.; Eustache, E.; Roussel, P.; Brillard, C.; Deresmes, D.; Nuns, N.; Rolland, N.; Brousse, T.; Lethien, C. Sputtered Titanium Nitride: A Bifunctional Material for Li-Ion Microbatteries. J. Electrochem. Soc. 2015, 162, A493-A500.

(5) Létiche, M.; Brousse, K.; Demortière, A.; Huang, P.; Daffos, B.; Pinaud, S.; Respaud, M.; Chaudret, B.; Roussel, P.; Buchaillot, L.; et al. Sputtered Titanium Carbide Thick Film for High Areal Energy on Chip Carbon-Based Micro-Supercapacitors. Adv. Funct. Mater. 2017, 27, 1606813.

(6) Mohamedi, M.; Makino, M.; Dokko, K.; Itoh, T.; Uchida, I.

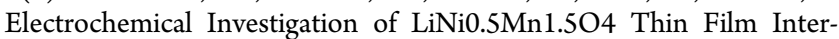
calation Electrodes. Electrochim. Acta 2002, 48, 79-84.

(7) Kunduraci, M.; Amatucci, G. G. Synthesis and Characterization of Nanostructured 4.7 V LixMn1.5Ni0.5O4 Spinels for High-Power Lithium-Ion Batteries. J. Electrochem. Soc. 2006, 153, A1345-A1352.

(8) Lee, J. H.; Kim, K. J. Structural and Electrochemical Evolution with Post-Annealing Temperature of Solution-Based LiNi0.5Mn1.5O4 Thin-Film Cathodes for Microbatteries with Cyclic Stability. Electrochim. Acta 2014, 137, 169-174.

(9) Xia, H.; Meng, Y. S.; Lu, L.; Ceder, G. Electrochemical Properties of Nonstoichiometric LiNi0.5Mn1.5O4 $-\delta$ Thin-Film Electrodes Prepared by Pulsed Laser Deposition. J. Electrochem. Soc. 2007, 154, A737-A743.

(10) Xia, H.; Tang, S. B.; Lu, L.; Meng, Y. S.; Ceder, G. The Influence of Preparation Conditions on Electrochemical Properties of LiNi0.5Mn1.5O4 Thin Film Electrodes by PLD. Electrochim. Acta 2007, 52, 2822-2828.

(11) Striebel, K. A.; Rougier, A.; Horne, C. R.; Reade, R. P.; Cairns, E. J. Electrochemical Studies of Substituted Spinel Thin Films. J. Electrochem. Soc. 1999, 146, 4339-4347.

(12) Baggetto, L.; Unocic, R. R.; Dudney, N. J.; Veith, G. M. Fabrication and Characterization of Li-Mn-Ni-O Sputtered Thin Film High Voltage Cathodes for Li-Ion Batteries. J. Power Sources 2012, 211, $108-118$.

(13) Li, J.; Baggetto, L.; Martha, S. K.; Veith, G. M.; Nanda, J.; Liang, C.; Dudney, N. J. An Artificial Solid Electrolyte Interphase Enables the Use of a $\mathrm{LiNi} 0.5 \mathrm{Mn} 1.5 \mathrm{O} 45 \mathrm{v}$ Cathode with Conventional Electrolytes. Adv. Energy Mater. 2013, 3, 1275-1278.

(14) Su, S. H.; Chiu, K. F.; Leu, H. J. Structural Evolution of Bias Sputtered LiNi0.5Mn1.5O4 Thin Film Cathodes for Lithium Ion Batteries. Thin Solid Films 2014, 572, 15-19.

(15) Konishi, H.; Suzuki, K.; Taminato, S.; Kim, K.; Kim, S.; Lim, J.; Hirayama, M.; Kanno, R. Structure and Electrochemical Properties of LiNi0.5Mn1.5O4 Epitaxial Thin Film Electrodes. J. Power Sources 2014, 246, 365-370.

(16) Tintignac, S.; Baddour-Hadjean, R.; Pereira-Ramos, J. P.; Salot, R. High Rate Bias Sputtered LiCoO2 Thin Films as Positive Electrode for All-Solid-State Lithium Microbatteries. Electrochim. Acta 2014, 146, $472-476$.

(17) Baddour-Hadjean, R.; Pereira-Ramos, J.-P. Raman Microspectrometry Applied to the Study of Electrode Materials for Lithium Batteries. Chem. Rev. 2010, 110, 1278-1319.

(18) Xie, J.; Imanishi, N.; Zhang, T.; Hirano, a.; Takeda, Y.; Yamamoto, O. Li-Ion Diffusion Kinetics in LiFePO4 Thin Film Prepared by Radio Frequency Magnetron Sputtering. Electrochim. Acta 2009, 54, 4631-4637.

(19) Zhu, X.-J.; Cheng, L.-B.; Wang, C.-G.; Guo, Z.-P.; Zhang, P.; Du, G.-D.; Liu, H.-K. Preparation and Characteristics of LiFePO 4
Thin Film by Radio Frequency Magnetron Sputtering for Lithium Microbatteries. J. Phys. Chem. C 2009, 113, 14518-14522.

(20) Baggetto, L.; Oudenhoven, J. F. M.; van Dongen, T.; Klootwijk, J. H.; Mulder, M.; Niessen, R. a. H.; de Croon, M. H. J. M.; Notten, P. H. L. On the Electrochemistry of an Anode Stack for All-Solid-State 3D-Integrated Batteries. J. Power Sources 2009, 189, 402-410.

(21) Hamon, Y.; Douard, a.; Sabary, F.; Marcel, C.; Vinatier, P.; Pecquenard, B.; Levasseur, A. Influence of Sputtering Conditions on Ionic Conductivity of LiPON Thin Films. Solid State Ionics 2006, 177, 257-261.

(22) Bates, J. Thin-Film Lithium and Lithium-Ion Batteries. Solid State Ionics 2000, 135, 33-45.

(23) Pichonat, T.; Lethien, C.; Tiercelin, N.; Godey, S.; Pichonat, E.; Roussel, P.; Colmont, M.; Rolland, P. A. Further Studies on the Lithium Phosphorus Oxynitride Solid Electrolyte. Mater. Chem. Phys. 2010, 123, 231-235.

(24) Taillades, G.; Benjelloun, N.; Sarradin, J.; Ribes, M. Metal-Based Very Thin Film Anodes for Lithium Ion Microbatteries. Solid State Ionics 2002, 152-153, 119-124.

(25) Phan, V. P.; Pecquenard, B.; Le Cras, F. High-Performance AllSolid-State Cells Fabricated With Silicon Electrodes. Adv. Funct. Mater. 2012, 22, 2580-2584.

(26) Pecquenard, B.; Le Cras, F.; Poinot, D.; Sicardy, O.; Manaud, J.P. Thorough Characterization of Sputtered $\mathrm{CuO}$ Thin Films Used as Conversion Material Electrodes for Lithium Batteries. ACS Appl. Mater. Interfaces 2014, 6, 3413-3420.

(27) Morcrette, M.; Barboux, P.; Perrière, J.; Brousse, T.; Traverse, A.; Boilot, J. P. Non-Stoichiometry in LiMn2O4 Thin Films by Laser Ablation. Solid State Ionics 2001, 138, 213-219.

(28) Reddy, M. V.; Pecquenard, B.; Vinatier, P.; Levasseur, A. Thin Films of Vanadium Oxide Grown on Vanadium Metal. Surf. Interface Anal. 2007, 39, 653-659.

(29) Cotte, S.; Pecquenard, B.; Le Cras, F.; Grissa, R.; Martinez, H.; Bourgeois, L. Lithium-Rich Manganese Oxide Spinel Thin Films as 3 V Electrode for Lithium Batteries. Electrochim. Acta 2015, 180, 528534.

(30) Ledwaba, R. S.; Matshaba, M. G.; Ngoepe, P. E. Molecular Dynamics Simulations of Spinels. LiMn2O4 and Li4Mn5O12 at High Temperatures. IOP Conf. Ser.: Mater. Sci. Eng. 2015, 80, 012024.

(31) Thornton, J. a. The Microstructure of Sputter-Deposited Coatings. J. Vac. Sci. Technol., A 1986, 4, 3059-3065.

(32) Detor, A. J.; Hodge, A. M.; Chason, E.; Wang, Y.; Xu, H.; Conyers, M.; Nikroo, A.; Hamza, A. Stress and Microstructure Evolution in Thick Sputtered Films. Acta Mater. 2009, 57, 2055-2065.

(33) Stelmakh, V.; Rinnerbauer, V.; Joannopoulos, J. D.; Soljačić, M.; Celanovic, I.; Senkevich, J. J.; Tucker, C.; Ives, T.; Shrader, R. Evolution of Sputtered Tungsten Coatings at High Temperature. J. Vac. Sci. Technol., A 2013, 31, 061505.

(34) Kulikovsky, V.; Vorlicek, V.; Ctvrtlik, R.; Bohac, P.; Jastrabik, L.; Lapsanska, H. Effect of Air Annealing on Mechanical Properties and Structure of Amorphous B4C Films. Surf. Coat. Technol. 2011, 205, 4052-4057.

(35) Letiche, M.; Eustache, E.; Freixas, J.; Demortiere, A.; De Andrade, V.; Morgenroth, L.; Tilmant, P.; Vaurette, F.; Troadec, D.; Roussel, P.; et al. Atomic Layer Deposition of Functional Layers for on Chip 3D Li-Ion All Solid State Microbattery. Adv. Energy Mater. 2017, 7, 1601402 .

(36) Kozen, A. C.; Pearse, A. J.; Lin, C.-F.; Noked, M.; Rubloff, G. W. Atomic Layer Deposition of the Solid Electrolyte LiPON. Chem. Mater. 2015, 27, 5324.

(37) Nisula, M.; Shindo, Y.; Koga, H.; Karppinen, M. Atomic Layer Deposition of Lithium Phosphorus Oxynitride. Chem. Mater. 2015, 27, 6987-6993.

(38) Yu, D. Y. W.; Yanagida, K.; Kato, Y.; Nakamura, H. Electrochemical Activities in Li2MnO3. J. Electrochem. Soc. 2009, 156, A417-A424.

(39) Lee, E.; Nam, K.-W.; Hu, E.; Manthiram, A. Influence of Doping on the Cation Ordering and Charge - Discharge Behavior of 
LiMn1.5Ni0.5O4 Spinel between 5 and 2 V. Chem. Mater. 2012, 24, 3610-3620.

(40) Amdouni, N.; Zaghib, K.; Gendron, F.; Mauger, A.; Julien, C. M. Structure and Insertion Properties of Disordered and Ordered LiNi $0.5 \mathrm{Mn} 1.5 \mathrm{O} 4$ Spinels Prepared by Wet Chemistry. Ionics 2006, 12, $117-126$.

(41) Allen, G. C.; Paul, M. Chemical Characterization of Transition Metal Spinel-Type Oxides by Infrared Spectroscopy. Appl. Spectrosc. 1995, 49, 451-458.

(42) Wang, L.; Li, H.; Huang, X.; Baudrin, E. A Comparative Study of Fd-3m and P4332 "LiNi0.5Mn1.5O4. Solid State Ionics 2011, 193, $32-38$.

(43) Julien, C. M.; Massot, M. Lattice Vibrations of Materials for Lithium Rechargeable Batteries III. Lithium Manganese Oxides. Mater. Sci. Eng., B 2003, 100, 69-78.

(44) Kim, J.; Chi, M.; Pieczonka, N. P. W.; Lee, E.; Bridges, C. A.; Tessema, M. M.; Manthiram, A.; Persson, K. A.; Powell, B. R.; Huq, A. Integrated Nano-Domains of Disordered and Ordered Spinel Phases in LiNi0.5Mn1.5O4 for Li-Ion Batteries. Chem. Mater. 2014, 26, 4377-4386.

(45) Aurbach, D.; Levi, M. D.; Levi, E.; Telier, H.; Markovsky, B.; Salitra, G. Common Electroanalytical Behavior of Li Intercalation Processes into Graphite and Transition Metal Oxides. J. Electrochem. Soc. 1998, 145, 3024-3034.

(46) Ho, C.; Raistrick, I. D.; Huggins, R. A. Application of A-C Techniques to the Study of Lithium Diffusion in Tungsten Trioxide Thin Films. J. Electrochem. Soc. 1980, 127, 343-350.

(47) Salzmann, I.; Resel, R. STEREOPOLE: Software for the Analysis of X-Ray Diffraction Pole Figures with IDL. J. Appl. Crystallogr. 2004, 37, 1029-1033.

(48) Liu, H.; Wang, J.; Zhang, X.; Zhou, D.; Qi, X.; Qiu, B.; Fang, J.; Kloepsch, R.; Schumacher, G.; Liu, Z.; et al. Morphological Evolution of High-Voltage Spinel LiNi0.5Mn1.5O4 Cathode Materials for Lithium-Ion Batteries: The Critical Effects of Surface Orientations and Particle Size. ACS Appl. Mater. Interfaces 2016, 8, 4661-4675.

(49) Eustache, E.; Tilmant, P.; Morgenroth, L.; Roussel, P.; Patriarche, G.; Troadec, D.; Rolland, N.; Brousse, T.; Lethien, C. Silicon-Microtube Scaffold Decorated with Anatase $\mathrm{TiO} 2$ as a Negative Electrode for a 3D Litium-Ion Microbattery. Adv. Energy Mater. 2014, 4, 1301612. 